$2017-12-01$

\title{
Current State of Practice Associated with the Use of Building Information Modeling (BIM) in the Custom Home Building Industry
}

William Noble Smith

Brigham Young University

Follow this and additional works at: https://scholarsarchive.byu.edu/etd

Part of the Construction Engineering and Management Commons

\section{BYU ScholarsArchive Citation}

Smith, William Noble, "Current State of Practice Associated with the Use of Building Information Modeling (BIM) in the Custom Home Building Industry" (2017). All Theses and Dissertations. 6632.

https://scholarsarchive.byu.edu/etd/6632 
Current State of Practice Associated with the Use of

Building Information Modeling (BIM) in the

Custom Home Building Industry

William Noble Smith

A thesis submitted to the faculty of

Brigham Young University

in partial fulfillment of the requirements for the degree of

Master of Science

James P. Smith, Chair

Kevin R. Miller

Evan D. Bingham

School of Technology

Brigham Young University

Copyright (C) 2017 William Noble Smith

All Rights Reserved 


\author{
ABSTRACT \\ Current State of Practice Associated with the Use of \\ Building Information Modeling (BIM) in the \\ Custom Home Building Industry \\ William Noble Smith \\ School of Technology, BYU \\ Master of Science
}

Building Information Modeling (BIM) has entered the construction industry and has permeated the commercial sector. Research is continually performed to expand the capabilities and applications within the industry. However, research has historically been mostly limited to the commercial sector and has seen little expansion to other sectors of the industry including the residential sector. The potential cause for this may be the limited number of industry professionals who utilize the software to the benefit of their companies. The focus of this study was specifically the custom home building sector of residential construction in the United States because of the unique and potentially complex nature of each project.

The study was performed using a Delphi Panel, which utilizes a panel of experts to reach a consensus on a given subject. In this study, the goal was to reach a consensus on the most common uses challenges and benefits of BIM within the residential sector. In the first questionnaires, the experts were asked to identify, with a series of demographic questions including the number of employees in their company, the number of homes they build each year, and the average sale price of each home. Each expert's responses to the demographic questions were cross-referenced with the responses concerning uses, benefits, and challenges to provide other industry members wishing to implement with relatable demographic references to compare with their own company demographics. The experts then identified how they used BIM, what benefits they had seen, and any challenges they faced. The uses, benefits, and challenges identified in this questionnaire were ranked in the following questionnaire to identify the most common uses, greatest benefits, and greatest challenges.

The top uses identified by this expert panel were design and visualization, the creation of construction documents, and quantity take-offs. The most common benefits identified by this panel were client visualization, plan accuracy, improved client communication, and ease of plan revisions. The most common challenges identified by this panel were high software costs, the steep learning curve when training employees, and the time-consuming nature of creating and maintain models correctly.

Keywords: building information modeling [BIM], custom home building, residential construction, delphi 


\section{ACKNOWLEDGEMENTS}

I would first and foremost like to thank my spouse and children for their constant support and encouragement. I would not be here today without them. I would also like to thank my committee and, specifically, my chair for his patience and diligence in helping me complete this process. His insight and expertise were invaluable throughout the course of this research. Finally, I would like to extend my deepest gratitude for the industry experts who took time out of their busy schedules to participate in this study. Their opinions and feedback made this research possible. 


\section{TABLE OF CONTENTS}

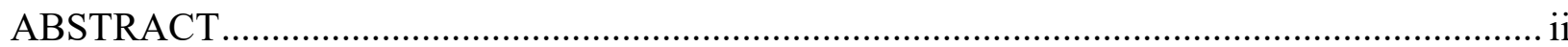

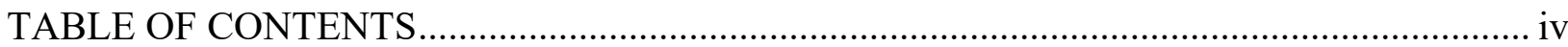

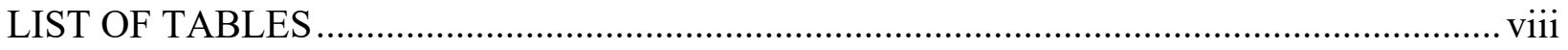

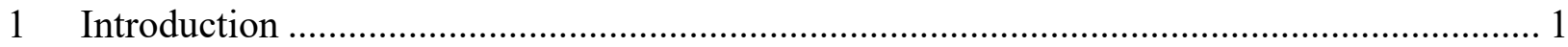

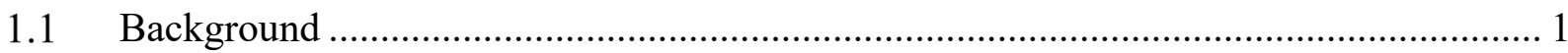

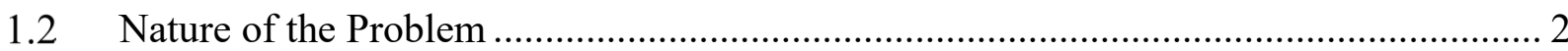

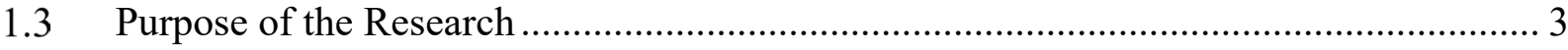

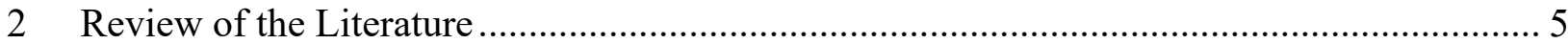

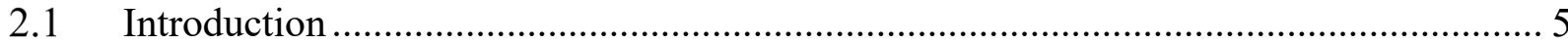

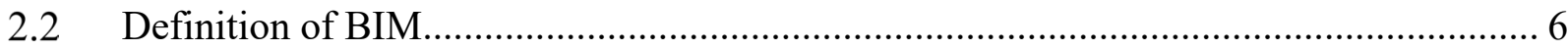

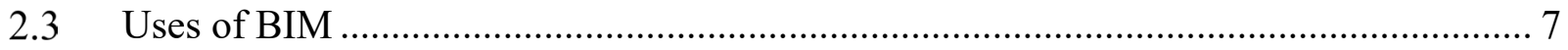

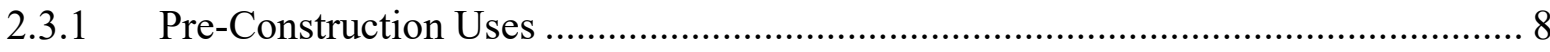

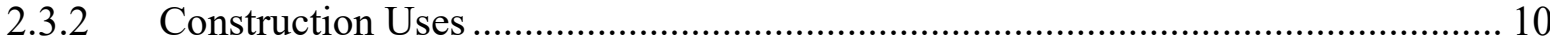

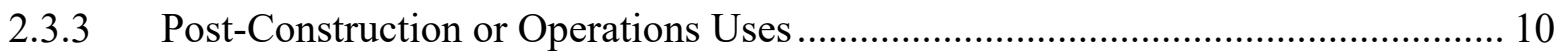

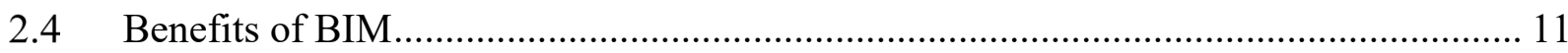

2.4.1 Benefits According to Industry Sector............................................................... 11

2.4.2 Potential Benefits for Residential Construction...................................................... 14

2.5 Risks Found in Commercial Applications .............................................................. 15

2.6 Differences Between Commercial and Residential................................................... 16 


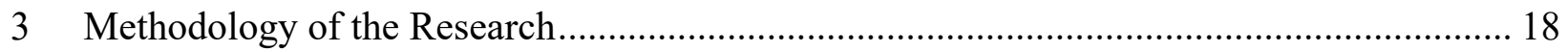

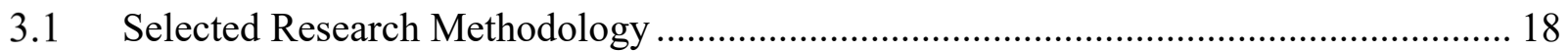

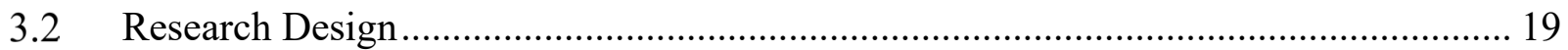

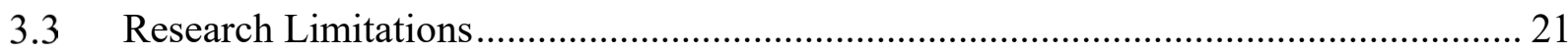

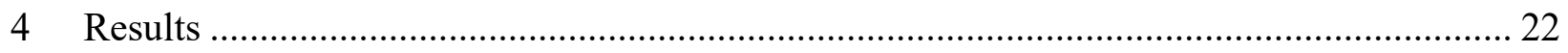

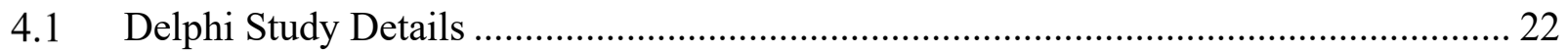

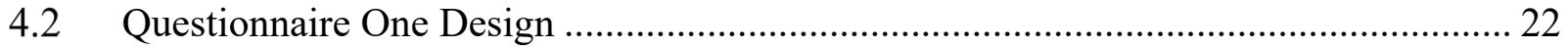

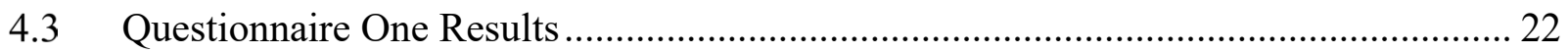

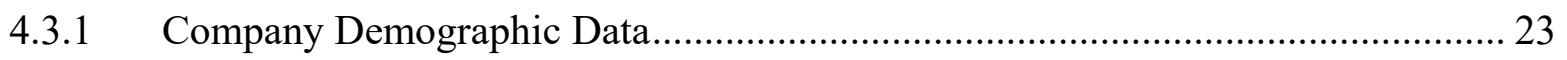

4.3.2 BIM Processes ........................................................................................... 25

4.3.3 BIM Uses, Benefits, and Challenges ............................................................... 26

4.3.4 Questionnaire 1 Cross-Tabulation Analysis ………............................................. 27

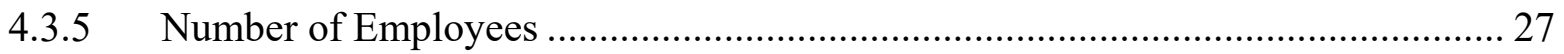

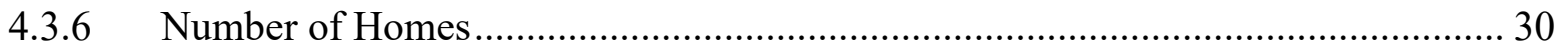

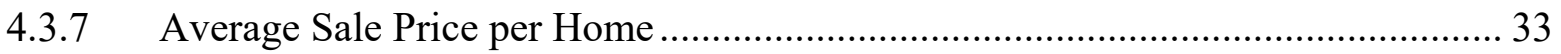

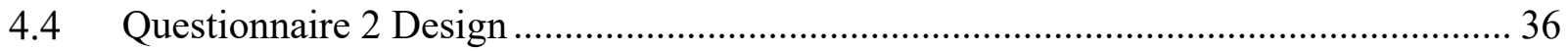

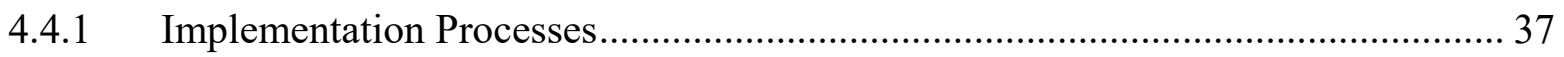

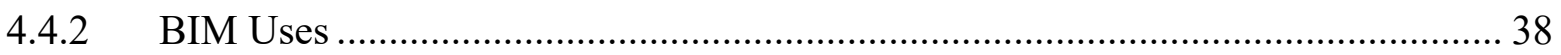

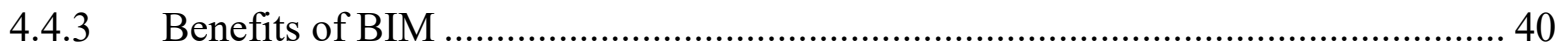

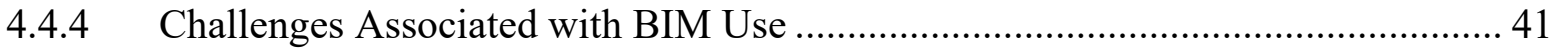


4.4.5 Questionnaire 2 Cross-Tabulation Analysis .................................................. 41

4.4.6 Number of Employees: Questionnaire 2 …................................................ 42

4.4.7 Number of Homes: Questionnaire 2 ............................................................. 46

4.4.8 Average Sale Price: Questionnaire 2 ......................................................... 50

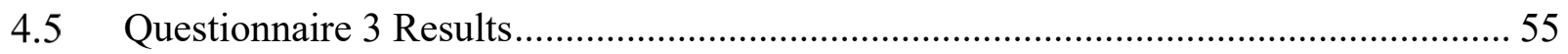

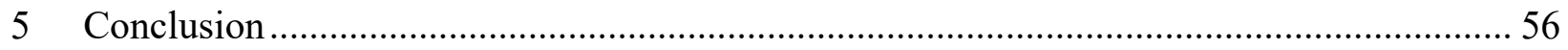

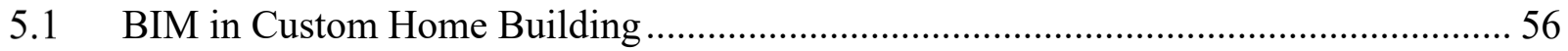

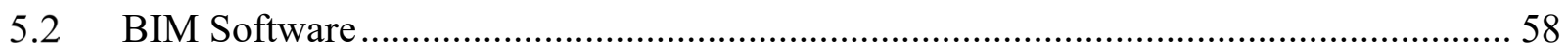

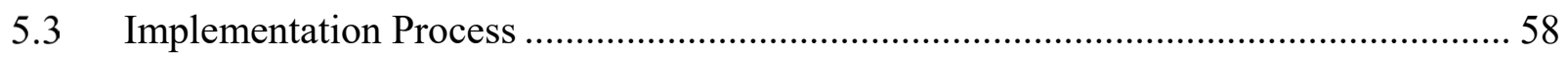

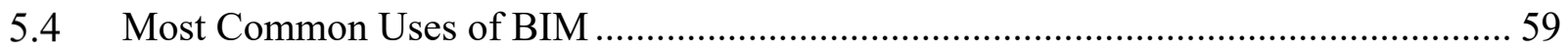

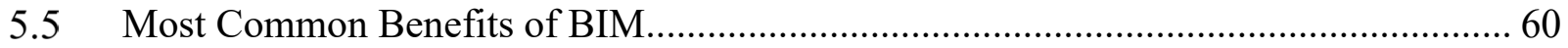

5.6 Most Common BIM Challenges ...................................................................... 63

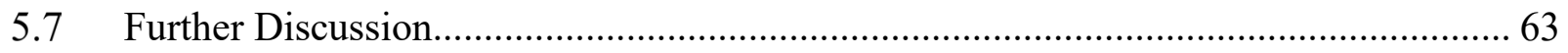

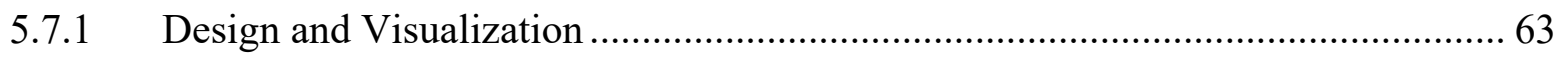

5.7.2 Creation of Construction Documents............................................................... 65

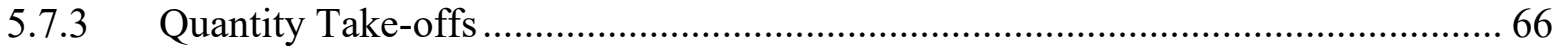

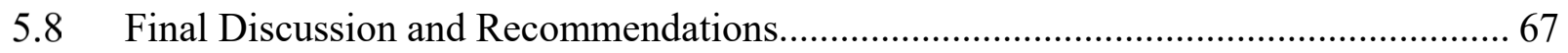

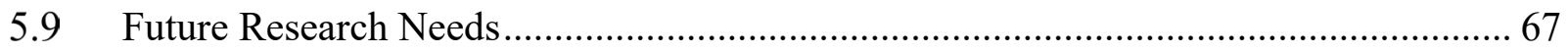

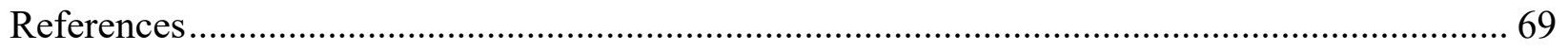

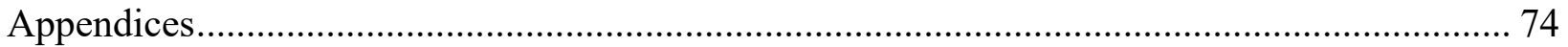


Appendix A. $\quad$ List of Expert Panel Members................................................................. 75

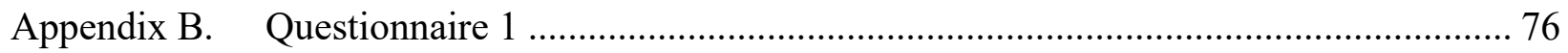

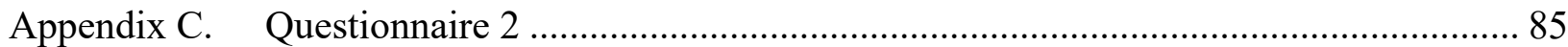

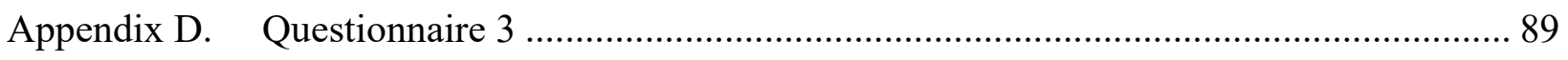




\section{LIST OF TABLES}

Table 2.1: Benefits for Each NAICS Construction Subsector ........................................................ 13

Table 2.2: Differences Between Commercial and Residential Construction ................................ 17

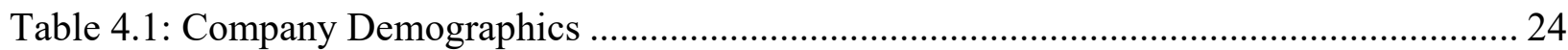

Table 4.2: Software and Implementation Process Utilized........................................................ 25

Table 4.3: BIM Uses Organized by Number of Employees ......................................................... 28

Table 4.4: BIM Benefits Organized by Number of Employees.................................................. 29

Table 4.5: BIM Challenges Organized by Number of Employees ................................................ 30

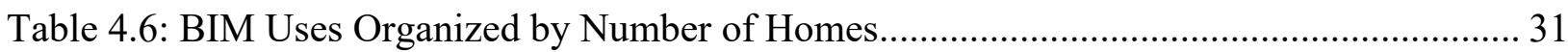

Table 4.7: BIM Benefits Organized by Number of Homes ......................................................... 32

Table 4.8: BIM Challenges Organized by Number of Homes....................................................... 33

Table 4.9: BIM Uses Organized by Average Sale Price............................................................. 34

Table 4.10: BIM Benefits Organized by Average Sale Price ......................................................... 35

Table 4.11: BIM Challenges Organized by Average Sale Price............................................... 36

Table 4.12: Implementation Processes Ranked in Questionnaire 2........................................... 37

Table 4.13: BIM Most Common Uses Listed Questionnaire 2 .................................................. 38

Table 4.14: BIM Most Commonly Utilized Uses Ranked in Questionnaire 2 ............................. 39

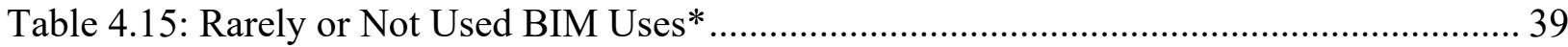

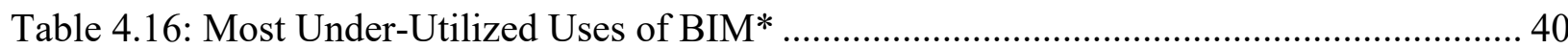

Table 4.17: BIM Benefits Ranked in Questionnaire 2 ................................................................ 40

Table 4.18: BIM Challenges Ranked in Questionnaire 2 …………………………….............. 41

Table 4.19: Most Common BIM Uses Organized by Number of Employees ............................... 43

Table 4.20: Ranked BIM Benefits Organized by Number of Employees ...................................... 44 
Table 4.21: Ranked BIM Challenges Organized by Number of Employees ............................ 45

Table 4.22: Most Common BIM Uses Organized by Number of Homes ............................... 47

Table 4.23: Ranked BIM Benefits Organized by Number of Homes..................................... 48

Table 4.24: Challenges of BIM as Ranked and Organized by Number of Homes ..................... 49

Table 4.25: Most Common BIM Uses Organized by Average Sale Price................................. 51

Table 4.26: Benefits of BIM as Ranked and Organized by Average Sale Price ....................... 52

Table 4.27: Ranked BIM Challenges Organized by Average Sale Price ................................ 54

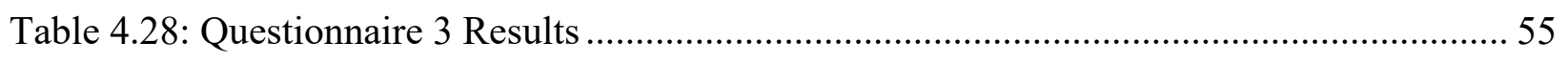

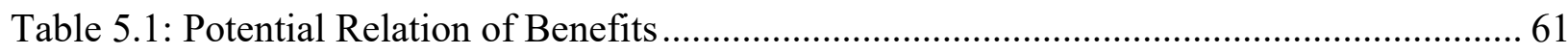




\section{LIST OF FIGURES}

Figure 1: BIM Uses Within the Project Execution Plan .............................................................. 8

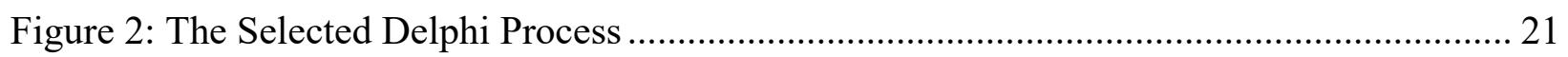




\section{INTRODUCTION}

\subsection{Background}

As the construction industry has grown, the means of communicating the construction documents, and any revisions to them, have changed (Rosenbloom, 2011 \& Beveridge, 2012). Technology and digital construction documents are at the forefront due to the sheer volume and increasingly complex nature of construction projects (Eveland, 2016). With the introduction of computer-aided design (CAD) in 1963 (Cadazz, 2004 \& Mark, 2008), the ability to digitally communicate and revise construction documents entered the industry. The technology has improved and evolved to a three-dimensional Building Information Modeling (BIM).

Building Information Modeling (BIM) is "the process of creating and using digital models for design, construction and/or operations of projects" (McGraw-Hill, 2009). It is also defined as "a digital representation of physical and functional characteristics of a [building]" that provides a "basis for decision making during its lifecycle..." (buildingSMARTalliance, 2015). These models can be used to aid design, assess risks, identify constructability issues, etc. (Beveridge, 2012). This software has permeated the construction industry and multiple benefits have been identified and used to the advantage of construction projects worldwide (McGraw-Hill, 2009). The construction sector can be divided into five subsectors; commercial, highway, heavy industrial, municipal utility, and residential. 
The value of BIM has been noted by government entities like the United Kingdom, who mandated in 2011 that by 2016 all government-procured projects would utilize fullycollaborative BIM. In their 2016 report, most departments had met that mandate (The Infrastructure and Projects Authority, 2016). States like Tennessee, Ohio, and Wisconsin have also implemented BIM Standards (TNF\&A, 2015 \& Ohio DAS General Services Division, 2010 \& WIDOA, 2009). Therefore, private commercial contractors, as well as governments, have recognized the value of BIM. Most commercial projects are unique in nature and BIM has become a key tool for managing each aspect of those unique projects. However, while the popularity of this software is increasing within the residential sector (Ford, 2016), it is not being utilized to the same degree.

\subsection{Nature of the Problem}

Residential construction represents approximately $40 \%$ of the construction value placed in December of 2016 (U. S. Census Bureau, 2016). With residential construction accounting for this much of the construction market in the United States, the use of BIM could provide immense benefits. While it is anticipated that all residential construction could benefit from BIM, the focus of this research was on the custom home sector. Like commercial construction, custom homes are unique and potentially just as complex as commercial construction. According to the NAHB, custom homes are defined as "one-of-a-kind, upscale creations that come with luxury upgrades and unique architectural design" (NAHB, 2017). Some government entities, while defining architectural fees, classify custom residential construction as complex and other residential construction as simple (New Mexico Administrative Code, 1.5.18.9 \& ADECA, 2015). The reasons for the slow adoption rate of BIM are varied and range from unawareness (NAHB, 2014) to high software costs (Nellis, 2012 \& Robinson, 2006). The software is, 
however, steadily entering the market. In a 2014 study, the National Association of Home Builders (NAHB) found that $15 \%$ of members were familiar with BIM, with $27 \%$ of those familiar with BIM currently using it. An additional $47 \%$ of members were interested in using the software in the future (NAHB, 2014). In a similar study conducted by the NAHB in 2016, they found that those numbers had increased to $26 \%$ of members who were familiar with BIM and $47 \%$ of those who were familiar with BIM currently using it (NAHB, 2016). The proposed research is to identify experts within the industry who currently utilize BIM and further identify how it is being implemented and any benefits and/or challenges in their processes of implementation.

Due to the limited use of BIM in single-family residential construction there has been little research performed pertaining to its use. Thus, there are limited resources for contractors wishing to implement BIM. In order to establish the need for and significance of this research, the review of the literature will identify the definition, uses, benefits, and risks of BIM as they pertain to the construction industry. Because of the relatively widespread use of BIM within the commercial construction sector and the respective similarities between it and residential construction, commercial construction provided the basis of comparison for the purposes of this study. Potential benefits to residential construction were identified. The differences between commercial and residential construction were also identified.

\subsection{Purpose of the Research}

The purpose of this research was to identify current best practices, benefits, and challenges associated with the use of BIM in custom home building companies in the United States. This provides a basis of understanding for companies desiring to implement BIM. The research questions were as follows: 
- What BIM software is being used?

- What is the best implementation process?

- What are the most common uses of BIM?

- What are the most common benefits of BIM?

- What are the most common challenges associated with BIM use? 


\section{REVIEW OF THE LITERATURE}

\subsection{Introduction}

The literature available on the use of BIM in residential construction is limited due to its relative adolescence in the single-family residential sector (Cambeiro, 2014). Literature specific to custom home building is limited even further. This may be caused by the low adoption rate by small to medium enterprises (Bhoir, 2015). A small to medium size enterprise is defined as a company with less than 500 employees and according to the United States Census Bureau, in 2014 the number of construction companies with less than 500 employees was 653,598 while the number of construction companies with more than 500 employees was 979 (U. S. Census Bureau, 2014). This data includes all construction companies. According to the NAHB, in 2009 the average number of employees in single-family home builder companies was 7.5 (Quint, 2010). Some research has been performed to identify resources for small home-building enterprises who would like to implement BIM. The study performed by Garcia and his associates provides data on software and provides guidelines for effective adoption of BIM. These guidelines include:

- External coaching during the initial adoption

- Creating BIM expertise either through training or hiring 
- Retention and motivation of BIM experts through increased levels of autonomy, task sharing among disciplines (architectural, structural, MEP), shared goals, and public recognition for good performance

- Participation in BIM knowledge sharing networks

The research performed by Garcia and his associates also states that BIM impacts residential companies through increased productivity, profitability, and competitive advantage, however, does not extend to actual practices within the industry (Garcia, 2016).

The Manrique study was performed with the perspective of how the use of BIM in the home design phase effects the creation of accurate shop drawings that in turn aids in the prefabrication of residential construction components as an offsite construction method (Manrique, 2015).

\subsection{Definition of BIM}

According to the National BIM Standard, BIM represents three distinct but related functions. It is a business process, a digital representation, and organization and control. The business process includes generating and leveraging the building data to design, construct and operate the building throughout its lifecycle. The digital representation provides the physical and functional characteristics that form a reliable basis for decision making throughout the lifecycle. Organization and control utilizes the digital prototype to benefit the sharing of information pertaining to many aspects of the buildings life including efficient design, site control, project documentation, etc. (buildingSMARTalliance, 2015).

BIM has also been defined by multiple studies (Eastman, 2008 \& McGraw-Hill, 2009 \& Woo, 2010 \& Succar, 2009). McGraw Hill (2009), for example, defines BIM as "the process of 
creating and using digital models for design, construction and/or operations of projects." For this research, the study performed by Zuppa best defined BIM as "a tool for visualizing and coordinating AEC work and avoiding errors and omissions and improving the productivity, schedule, safety, cost, and quality of construction projects" (Zuppa, 2009).

\subsection{Uses of BIM}

As described by the National BIM Standard, BIM is a function that aids decision making and building operation throughout the building lifecycle. This is generally divided into three timeframes; pre-construction, during construction, and post-construction or operation (buildingSMARTalliance, 2015). Similarly, in 2011, the Computer Integrated Construction (CIC) Research program compiled a list of 25 uses of BIM through a series of interviews with industry experts, analysis of implementation, and a review of the literature. The CIC research also compiled descriptions of each use. They grouped each use in the following 4 phases:

- Plan

- Design

- Construct

- Operate

Some uses, however, have some carryover through multiple phases of construction as indicated by the following diagram from the CIC website. 


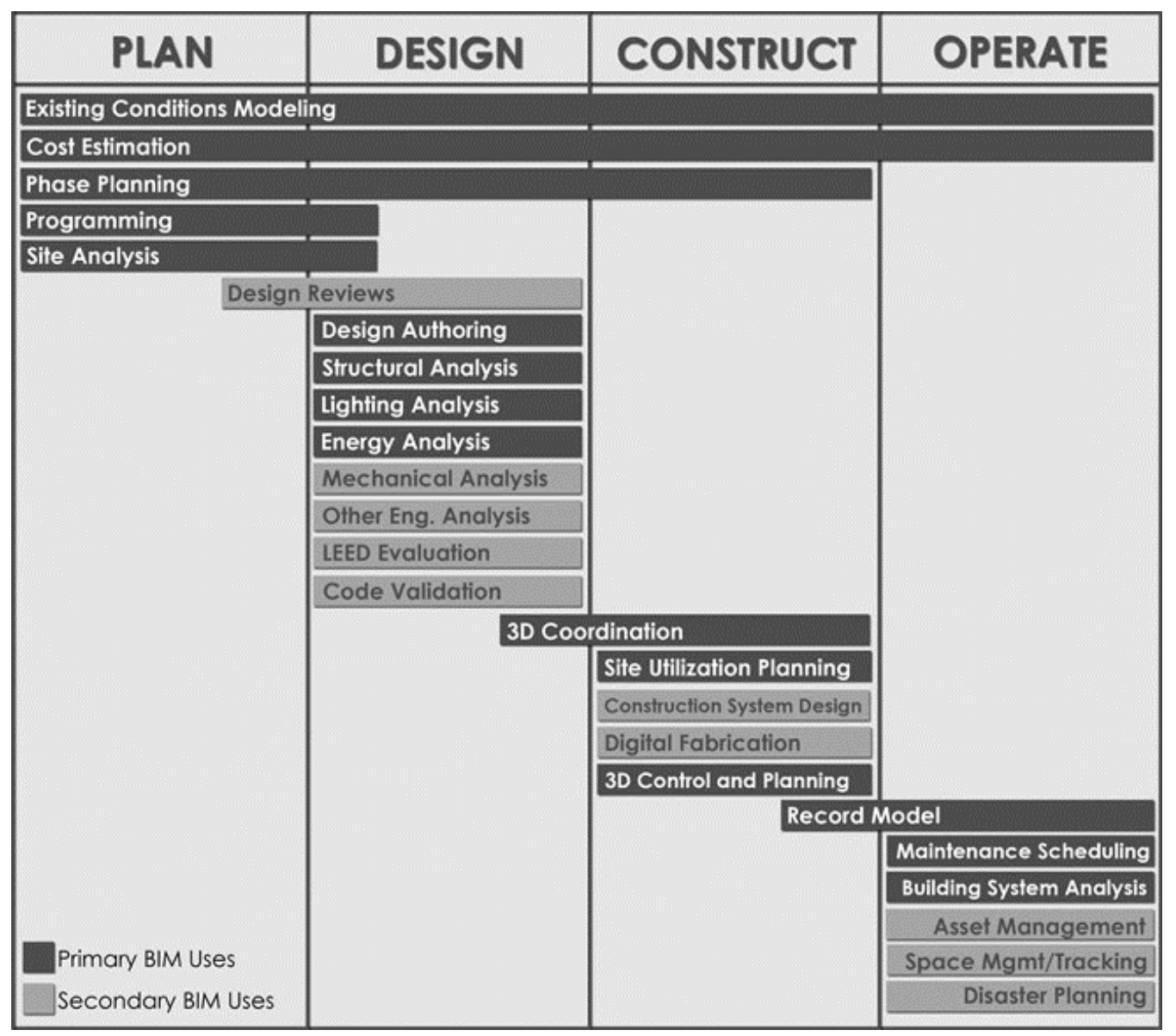

Figure 1: BIM Uses Within the Project Execution Plan (CIC,2011)

For the purposes of this research, the plan and design categories were combined to create the pre-construction phase. Specific focus was placed on the primary uses of BIM identified in the above diagram.

\subsubsection{Pre-Construction Uses}

$\mathrm{BIM}$ is used in preconstruction for clash detection, quantity take-offs and design conceptualization (Eastman, 2008). The model can also be used in project scheduling analysis and cost estimation, commonly referred as 4D and 5D (Succar, 2009). The CIC also lists existing 
conditions modeling, programming, site analysis, structural analysis, lighting analysis, and energy analysis as other uses of BIM.

Clash detection identifies spatial conflicts such as a duct and conduit occupying the same space as structural elements (Levy, 2006). A 2012 study identified clash detection as one of the most common uses of BIM among general commercial contractors (Beveridge, 2012).

Quantity take-offs, cost estimation, or any other project related financial processes through BIM potentially provides quick and accurate material quantities and costs data that could aid significantly in design and other decision-making processes throughout the product lifecycle (CIC, 2011).

Design conceptualization was a common use of BIM which allows for better visualization using a 3D model for stakeholders. This increased the collaboration between stakeholders that contributed to the increased transparency during the design processes. This transparency can even extend to the cost and scheduling activities of a project (CIC, 2011).

Existing conditions modeling involves the creation of a model through either manual creation via conventional surveying methods or the use of laser-scanning technologies to create a model that can be used for many purposes including future modeling, design coordination, or remodel/renovation activities (CIC, 2011). This is also closely related to site analysis, which can aid in the determination of the optimal location for a project on a site and can then be used to decrease costs related to demolition and utility demand (CIC, 2011).

The structural, electrical, and energy analysis uses of BIM are used to improve the design and energy consumption of a facility throughout its lifecycle. This can potentially translate to higher returns on investment for stakeholders by reducing life-cycle costs. 


\subsubsection{Construction Uses}

The uses during construction have been identified as the following: project coordination and management, and offsite fabrication (Eastman, 2008). The CIC also defines project site planning, 3D control, and planning.

Project coordination and management and site planning, in conjunction with phase planning, provide increased productivity and efficiency. BIM allows for the creation of feasible construction schemes and recognition of potential conflicts with site space and time. This can include clash detection and other coordination activities. As BIM improves coordination and design, the potential for offsite fabrication of construction materials and elements may reduce waste and improve efficiency. BIM also allows for 3D elements to be applied to "real-world" coordinates which can reduce language barriers and reduce field errors and rework because each element of the project has a control point that can be derived from the model.

\subsubsection{Post-Construction or Operations Uses}

Facility management processes were improved significantly with an accurate model through real-time energy-related data (Woo, 2010). The CIC also defines building maintenance

scheduling and system analysis as operations uses. BIM aids in the management and creation of maintenance schedules because all of the elements of a facility have been input into a model where product life and maintenance requirements can be stored. Because all systems have been included in the model, energy analysis may be performed. The efficiency of maintenance personnel may also increase because the physical location of all systems components may be found in the model. 


\subsection{Benefits of BIM}

BIM benefits construction in the processes of preconstruction, design, construction and post-construction (Eastman, 2008). Through a review of the literature, the benefits of BIM that have been identified by previous research are:

- Increased project quality (Bryde, 2013 \& Manrique, 2015 \& Suermann, 2009)

- Reduced project costs (Azhar, 2011 \& Borup, 2007 \& Bryde, 2013 \& Giel, 2013 \& Manrique, 2015 \& Suermann, 2009 \& Traynor, 2009 \& Chong, 2016)

- Decreased project schedule (Bryde, 2013 \& Manrique, 2015 \& Suermann, 2009 \& Chong, 2016)

- Increased productivity (Borup, 2007 \& Francom, 2015 \& Manrique, 2015 \& Suermann, 2009)

- Increased jobsite safety (Suermann, 2009)

- Increased trade coordination (Bryde, 2013 \& Bynum, 2013 \& Hanna, 2013 \& Lu, 2015 \& Woo, 2010 \& Gourlis, 2017 \& Sibert, 2013)

- Increased communication (Bryde, 2013 \& Borup, 2007 \& Childress, 2014 \& Francom, 2015 \& McGraw Hill Construction, 2014 \& Poirier, 2015)

Many of these benefits can be found in multiple stages of a project and throughout the entirety of a project's life-cycle.

\subsubsection{Benefits According to Industry Sector}

According to the North American Industry Classification System (NAICS) list found on the United States Department of Labor: Bureau of Labor Statistics (BLS) website, the construction sector is divided into two main sub-sectors: building construction and heavy and 
civil engineering construction (NAICS, 2017). The NAICS further divides the industry into smaller subsectors. Building construction is divided into residential and non-residential. Nonresidential is then divided into commercial and industrial construction. Heavy and civil engineering construction is divided into utility system, land subdivision, and highway (BLS, 2017). Table 2.1 identifies the benefits of BIM in the various subsectors.

Table 2.1 presents a list of benefits that have been identified through a review of the literature. It is not a comprehensive list. Any blank spaces in the table indicate a lack of data relating to that respective sector. While this study is not a comprehensive literature review on the global benefits of BIM throughout the construction industry, it does provide a valuable overview of the benefits that have been identified and identifies several future research needs. It also provided useful data to further establish the need for this study.

Scholarly resources for commercial construction are abundant. Those resources acknowledge the benefits of BIM to varying degrees. BIM has been found to positively impact the following key performance indicators: (1) quality, (2) cost, (3) schedule, (4) productivity, and (5) safety, with quality and cost receiving the greatest impact (Suermann, 2009). Per Bryde, (2013), the use of BIM also produces a positive effect on quality, coordination, communication and time (with time being measured from project conception to completion). BIM has also been found to benefit consumer involvement and overall productivity (Borup, 2007 \& Francom, 2015). Project owners/consumers have identified increased communication and coordination as a key (McGraw Hill Construction, 2014 \& Childress, 2014 \& Poirier, 2015).

Benefits are also identified specifically in the design stage (Eastman, 2008), the longest and most frequent use of BIM (McGraw Hill Construction, 2012). The design stage is shorter due to BIM "providing a platform for examination of design options, early involvement of all 


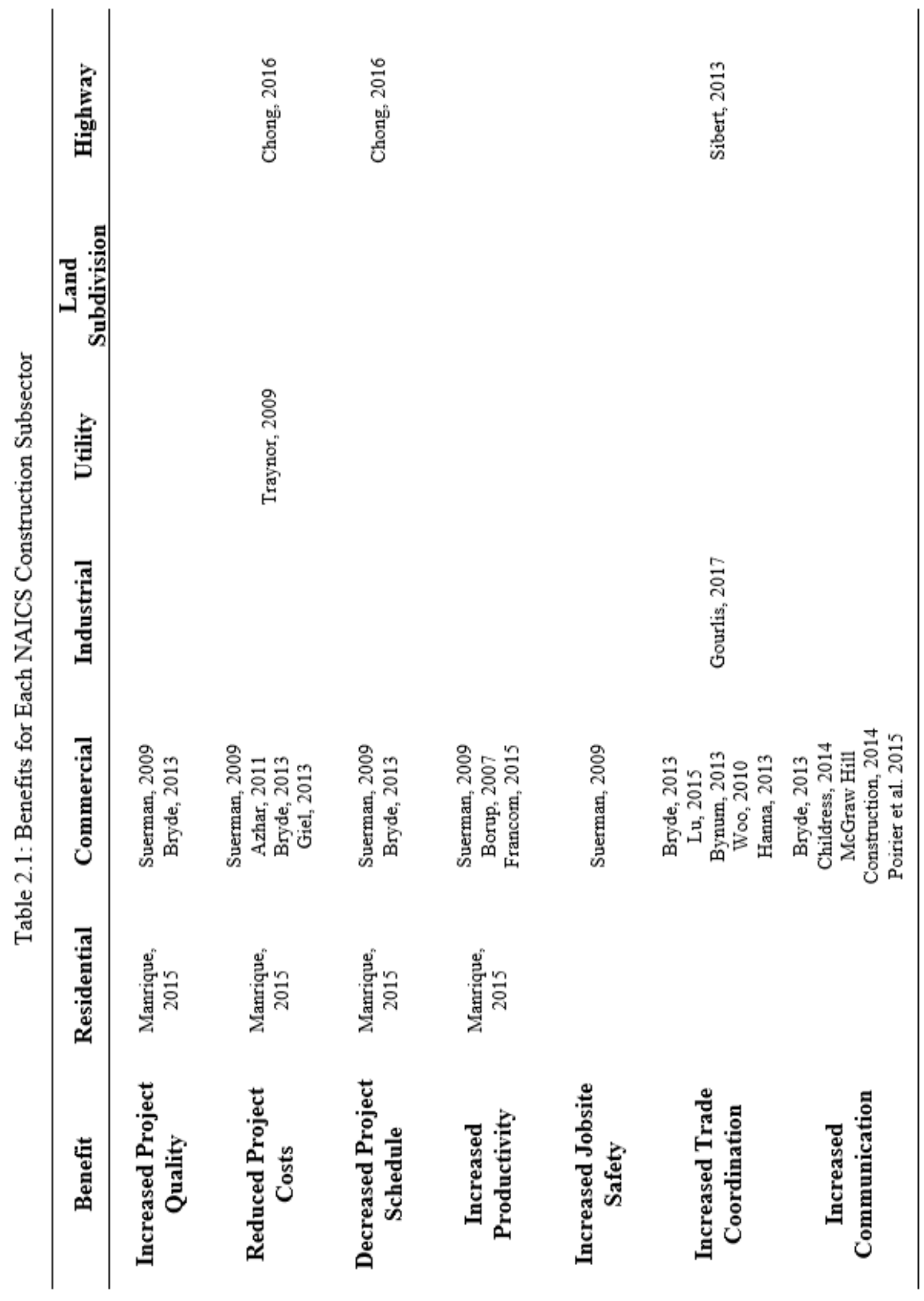


team members, and open information sharing" ( $\mathrm{Lu}, 2015)$. BIM fosters collaboration and eases the transition from design to construction (Bynum, 2013).

The financial benefits for commercial products have been studied and determined to produce a positive return on investment (Azhar, 2011 \& Bryde, 2013 \& Giel, 2013 \& McGrawHill, 2009). Azhar also quantified benefits to projects in a series of case studies in which they identified clashes and collisions which resulted in significant project benefits to cost and time savings. Cost and time savings were also found in the reduction of costly redesign throughout the project life cycle.

\subsubsection{Potential Benefits for Residential Construction}

Though residential construction has many differences in means and methods, the complexity of projects, specifically custom homes, can be similar to, if not greater than, commercial projects (ADECA, 2015 \& New Mexico Administrative Code, 1.5.18.9). According to the National Association of Home Builders (NAHB), BIM can benefit residential construction through consistent drawings, accurate cost estimates, accurate bills of materials and spatial conflict and system clash detection (NAHB 2012).

According to the NAHB, between the years of 2007 and 2012, the number of residential builders dropped by over 50\% (Quint, 2015). It is recognized that due to the economic recession that occurred during this period of time, many firms were unable to stay in business. However, there were many that were able to remain open. Success factors have been identified that could have contributed to these companies' abilities to stay open. In a 2005 study that aimed to identify success factors of small-volume home builders, 78 factors were identified. It is important to note that quality workmanship and products, customer communications and relations, 
scheduling/cycle time, and focus on product design were listed among the top ten factors of success (Hutchings, 2005).

The factors of success identified by the Hutchings study are particularly pertinent to the use of BIM for residential construction because of related key benefits of BIM found in commercial construction. For example, increased comunication and collaboration could greatly affect the success factor of customer communications and relations (McGraw Hill Construction, 2014 \& Poirier, 2015 \& Borup, 2007 \& Childress, 2014 \& Bynum, 2013). Increased quality and decreased costs due to early detection of defects and fewer change orders could affect the success factors of quality workmanship and products as well as scheduling and cycle-time (Borup, 2007 \& Suermann, 2009 \& Francom, 2015 \& Hanna, 2013). Benefits to the overall schedule clearly affect the success factor of scheduling and cycle time (Suermann, 2009 \& Bryde, 2013). The design elements inherent in the use of BIM affect the focus on product design (McGraw Hill Construction, 2012 \& Suermann, 2009 \& Francom, 2015). The comparison between these success factors and the benefits identified provide evidence for the potential benefit to residential construction.

\subsection{Risks Found in Commercial Applications}

Risks associated with BIM have been identified and classified as both legal and technical (Azhar, 2011). The following legal risks have been identified (Thomson, 2016):

- Ownership of BIM data with its associated copyright concerns

- Licensing issues

- Control of data entry and responsibility of inaccuracies 
- Blurred level of responsibility and fault for concerns

- Responsibility for the technological interface between various programs

Technological risks are as follows: "The need for well-defined transactional construction process models to eliminate data interoperability issues, the requirement that digital design data be computable, and the need for well-developed practical strategies for the purposeful exchange and integration of meaningful information among the building information model components" (Azhar 2011). Eastman, (2008) also defines a number of challenges that accompany the use of BIM.

\subsection{Differences Between Commercial and Residential}

According to the textbook Construction Management Jump Start, by Barbara J. Jackson (2010), Commercial and Residential construction have numerous differences in means, methods, and materials. They also employ different equipment types, structural frameworks, manufacturers, suppliers, specialty contractors, and sources of funding. The following table enumerates many of the crucial differences between the two sectors; however, it is assumed that the residential characteristics listed here apply mainly to production home builders and may not apply to the custom home-building sector that is the focus of this study. 
Table 2.2: Differences Between Commercial and Residential Construction

\begin{tabular}{|c|c|c|}
\hline AREAS OF INTEREST & COMMERCIAL & RESIDENTIAL \\
\hline FUNDING & $\begin{array}{l}\text { Private, public, or private-public } \\
\text { partnership. Large sums of money. } \\
\text { Corporations, agencies, or the } \\
\text { government. }\end{array}$ & Private individuals or developers \\
\hline PROJECT DURATION & Can take 3 years or more & Typically 3-6 months \\
\hline $\begin{array}{l}\text { SPECIALTY CONTRACTORS } \\
\text { NEEDED }\end{array}$ & $\begin{array}{l}\text { Yes (ex. Ironworkers, pipefitters, } \\
\text { glaziers) }\end{array}$ & Not typically \\
\hline $\begin{array}{l}\text { SPECIALTY ENGINEERS } \\
\text { NEEDED }\end{array}$ & Yes & No \\
\hline $\begin{array}{l}\text { PRIMARY TOOLS AND } \\
\text { EQUIPMENT NEEDED }\end{array}$ & $\begin{array}{l}\text { Commonly seen: Cranes, pile drivers, } \\
\text { concrete pumps, and welding machines, } \\
\text { concrete casting beds, cofferdams, and } \\
\text { slip forms }\end{array}$ & $\begin{array}{l}\text { Commonly seen: pneumatic air } \\
\text { nailers, nails, drills, saws }\end{array}$ \\
\hline EASE OF ENTRY & & Relatively easy \\
\hline $\begin{array}{l}\text { PRIMARY STRUCTURAL } \\
\text { MATERIALS }\end{array}$ & Concrete and steel & Small wood framing members. \\
\hline $\begin{array}{c}\text { PRIMARY EXTERIOR FINISH } \\
\text { MATERIALS }\end{array}$ & $\begin{array}{l}\text { Glass, brick, concrete, stone, aluminum, } \\
\text { steel, Exterior insulation panel. }\end{array}$ & $\begin{array}{l}\text { Wood or vinyl siding, brick or } \\
\text { stone, stucco }\end{array}$ \\
\hline PRIMARY ROOF MATERIALS & $\begin{array}{l}\text { Flat roof covered in a bituminous } \\
\text { membrane with a gravel ballast or a vinyl } \\
\text { or rubber covering, pitched roofs of } \\
\text { commercial buildings covered with } \\
\text { prefinished metal roofing. }\end{array}$ & $\begin{array}{l}\text { Pitched roof with shingles made of } \\
\text { asphalt, clay, concrete, or slate }\end{array}$ \\
\hline $\begin{array}{c}\text { PRIMARY INTERIOR FINISH } \\
\text { MATERIALS }\end{array}$ & $\begin{array}{l}\text { Light gauge steel studs covered in } \\
\text { drywall, paint, wall, coverings, carpet, } \\
\text { tile marble, granite, and acoustical ceiling } \\
\text { tiles. }\end{array}$ & $\begin{array}{l}\text { Drywall partitions and ceilings } \\
\text { with paint or wall coverings. } \\
\text { Carpet, tile, hardwood, laminate, or } \\
\text { sheet vinyl flooring }\end{array}$ \\
\hline $\begin{array}{c}\text { CLIENTELE } \\
\text { CHARACTERISTICS }\end{array}$ & $\begin{array}{l}\text { Less personal, the owners are less } \\
\text { concerned with day-to-day operations but } \\
\text { rather meeting the schedule and getting } \\
\text { into the building to use it for its intended } \\
\text { purpose. }\end{array}$ & $\begin{array}{l}\text { Individual families, emotional, } \\
\text { inexperienced }\end{array}$ \\
\hline $\begin{array}{l}\text { SCOPE OF KNOWLEDGE } \\
\text { NEEDED }\end{array}$ & $\begin{array}{l}\text { A deep understanding of construction } \\
\text { processes and techniques. Construction } \\
\text { managers are rarely involved in sales or } \\
\text { marketing or land acquisition. }\end{array}$ & $\begin{array}{l}\text { Sales, marketing, financing, land } \\
\text { development, entitlement, building } \\
\text { codes, purchasing, construction } \\
\text { operations, customer service, and } \\
\text { warranty }\end{array}$ \\
\hline
\end{tabular}




\section{METHODOLOGY OF THE RESEARCH}

\subsection{Selected Research Methodology}

The selected method of research to obtain the data required to define the current state of practice with the use of BIM in the custom home building industry was the Delphi method. This method utilizes multiple questionnaires in sequence to obtain consensus among a panel of experts. The research design selected relies on a moderately sized sample that is comprised of experts who take part in a series of questionnaires to obtain a consensus. Therefore, the sample must remain small to moderate in size to minimize the risk of not reaching consensus. The sample size was also dependent on availability and contains extra participants to account for nonrespondents.

The characteristics of Delphi (Sourani, 2015) are defined as:

- Anonymity: Opinions are gathered by means of a questionnaire that is kept anonymous from the other participants and can be changed by experts without public scrutiny. This anonymity must be maintained at all levels.

- Iteration with controlled feedback: The use of consecutive rounds to first obtain exploratory data which was codified and returned to experts.

- Statistical group response: The codified data was ranked by level of importance in subsequent questionnaires until a minimum of three practices and issues were identified. 


\subsection{Research Design}

The intent of this research was to identify the current best practices, benefits, and challenges that accompany the use of BIM in custom home building. An excellent source for these best practices were experts in the field who have successfully implemented this technology. For the purposes of this research, an expert was defined as an industry professional who utilizes BIM and uses it as a feature of their home building process. Therefore, they provided qualified insight and opinion on its application in residential construction. The recruitment process began through examination of company websites to build a preliminary list of possible experts. Once the list had been compiled through the initial examination of websites, each expert was called over the phone to confirm their use of BIM and to obtain their consent to participate.

The risks to the participants were minimal. They were asked to identify limited demographics such as the number of employees and number of homes completed each year.

The Delphi method was used to first gain exploratory data that identifies current practices. The exploratory data was then coded. As responses were read, preliminary categories were established per frequent words and phrases used by participants. The responses were then coded by the categories that were established. After the responses were coded, the categories and codes were reviewed to verify the accuracy of coding and ensure categories were appropriate. A second follow-up questionnaire was populated by the categories identified in the analysis of the first questionnaire. The categories were sent to the participants who ranked them in order of importance. Analysis of this data was performed through a calculation of the mean of the responses. A third questionnaire, was formulated using the results from the previous questionnaire. Using a Likert-type scale ranging from either 1 to 4 or 1 to 5 , the participants stated their level of agreement with the rankings determined in the second questionnaire. The 
scales are based on question type. A 1-4 scale is used for questions with a level of accuracy rating with the following categories:

1. Completely Accurate

2. Accurate

3. Inaccurate

4. Completely Inaccurate

A 1-5 scale is used for questions with a level of agreement rating with the following categories:

1. Completely Agree

2. Mostly Agree

3. Neither Agree nor Disagree

4. Mostly Disagree

5. Completely Disagree

The analysis of questionnaire 3 was similar to the second questionnaire. Consensus was identified as $75 \%$ or more of participants ranking a category the same (Sourani, 2015).

The process outlined in Figure 2.1 was implemented to obtain, rank and seek a consensus concerning the data (Smith 2011).

The Delphi method was selected because it provides an effective means of obtaining accurate information that is currently unavailable, studies an area where there is little-agreed knowledge, “combining fragmentary perspectives into a collective understanding," and models a real-world phenomenon with a range of viewpoints and "little established quantitative evidence" (Sourani \& Sohail, 2015). 
Selection of an expert panel to participate in the process

1.Codified opinions are used to develop the second questionnaire (possible testing).

1.Second questionnaire is transmitted to the participants who then rank the opinions obtained in the first questionnaire.
1.Development of the first-

round exploratory questionnaire
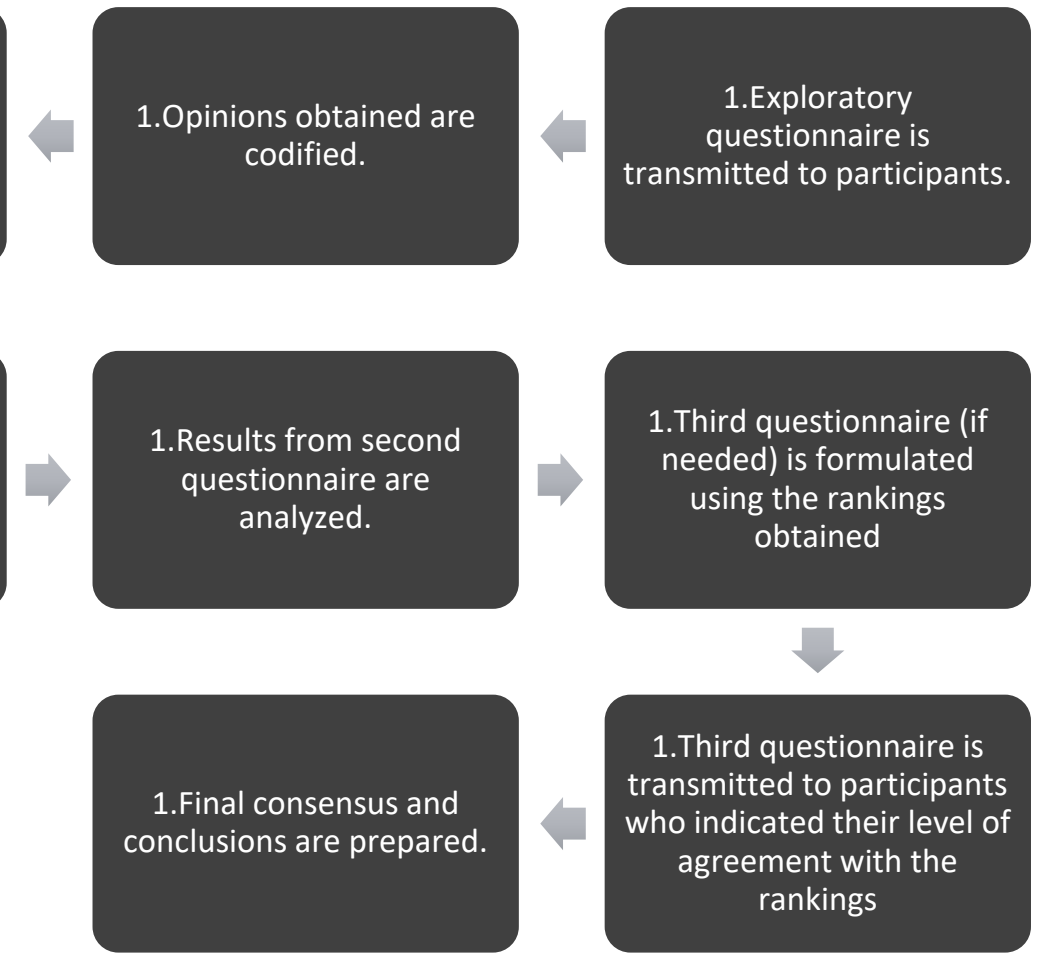

Figure 2.1: The Selected Delphi Process

\subsection{Research Limitations}

Because of the selected research design, there are limitations inherent in the process. The Delphi panel requires a small sample size of experts. The small sample size does not allow for data that can be generalized to the market. As such the data does not allow us to make population inferences. Additionally, all participants of this study were located in the United States. 


\section{RESULTS}

\subsection{Delphi Study Details}

This chapter defines the results of the Delphi study performed in this research. Initially 53 contractors and designers were contacted who currently use BIM in their business practices. For a list of the contractors who initially agreed to participate, see Appendix A. 18 experts agreed to participate and completed the first questionnaire. The second questionnaire had a response rate of $83 \%$ with 15 of 18 participants responding. The third and final questionnaire had a response rate of $56 \%$ with 10 of 18 participants responding. The research purpose was achieved with three rounds of questionnaires and therefore no further questionnaires were administered.

\subsection{Questionnaire One Design}

Questionnaire 1 (see Appendix B) was designed as an exploratory questionnaire comprised of mainly open-ended questions based on company demographics, BIM implementation, BIM use, benefits of BIM and challenges of BIM use. The answers to these questions provided the basis of study for the following questionnaires. The open-ended nature of the questions allowed for the participants to direct the study without being influenced by the questionnaire.

\subsection{Questionnaire One Results}

The following sections outline the results of each individual question. The question topics were as follows: 
- Demographics

- Company Location

- Number of Employees

- Number of Homes Completed Each Year

- Average Sale Price of Homes Sold

- Area of Specialization within the Industry

- What Software is Utilized

- Process of Implementation

- BIM Uses

- Benefits of BIM

- Challenges or Issues Associated with BIM Use

\subsubsection{Company Demographic Data}

The participants were asked to identify where their company is located based on region. Participants were permitted to select multiple locations to allow for those who do business in multiple regions to indicate that. Most of the participants listed the Mountain West region as a location where they did business.

The participants were asked to identify their number of employees with the following ranges of $1-10,11-25,26-50$, and $51+$. Most of the participants had relatively small companies with $72 \%$ reporting $1-10$ employees.

The participants were asked to identify the average number of homes their company completes each year using the following ranges: $0-10,11-30,31-60$, and $61+$. The majority of the participants, $68 \%$, indicated that they only completed $1-10$ homes per year.

The participants were asked to indicate the average sale price of their homes using the following ranges: Under $\$ 250,000 ; \$ 250,001-\$ 500,000 ; \$ 500,001-\$ 750,000 ; \$ 750,001$ $\$ 1,000,000$; and $\$ 1,000,001+$. 
The final demographics question asked what subsector they specialized in, with the categories being: new home construction, home remodeling, and home additions. The participants were able to select multiple categories. Table 4.1 lists all the demographic data received from the panel.

The roles of the employees were also identified. Nine participants were company owners, four were BIM managers, three were designers, one was a project manager, and one was a purchasing manager. While attempts were made to have multiple roles from the same company participate in the study, there was only one participant from each company. For a comprehensive list of all participants, please refer to Appendix A.

Table 4.1: Company Demographics

\begin{tabular}{ccc}
\hline Demographic Segment & Participants' Selections & $\%$ \\
\hline Company Location* & 12 & $67 \%$ \\
Mountain West & 4 & $22 \%$ \\
West Coast & 3 & $17 \%$ \\
Midwest & 2 & $11 \%$ \\
South & & $72 \%$ \\
Number of Employees & 13 & $17 \%$ \\
$1-10$ & 3 & $6 \%$ \\
$11-25$ & 1 & $6 \%$ \\
$26-50$ & 1 & $67 \%$ \\
$51+$ & & $28 \%$ \\
0-10 & 12 & $6 \%$ \\
11-30 & 5 & $39 \%$ \\
Sumber of Homes Completed Each Year & 1 & $33 \%$ \\
\$250,001-\$500,000 & & $17 \%$ \\
\$1,000,001 & 7 & $11 \%$ \\
\$500,001-\$750,000 & 6 & $100 \%$ \\
\$750,001-\$1,000,000 & 3 & $33 \%$ \\
New Home Construction & 2 & $28 \%$ \\
Home Remodeling & & \\
Home Renovation & 18 & $50 \%$ \\
Company Owner & 6 & $22 \%$ \\
BIM Manager & 5 & $6 \%$ \\
Designer & & $6 \%$ \\
Project Manager & 9 & \\
Purchasing Manager & & \\
Participant of the 18 total participants selected multiple of the provided options & \\
\hline
\end{tabular}




\subsubsection{BIM Processes}

Following the demographics questions, participants were asked to identify what software they utilized within their company and the method(s) they used to implement BIM in their company.

The most common software platform for BIM in the residential market, as identified by this panel, is Autodesk ${ }^{\circledR}$ Revit $^{\circledR}$. There are however other platforms that are being utilized with some success.

The participants were asked to identify what process they used to implement BIM within their company. The implementation processes which were identified can be found in Table 4.2. The chart also shows the number, and resultant percentage, of participants who listed each process and the number and percentage of experts, in this panel, who use a given software.

Table 4.2: Software and Implementation Process Utilized

\begin{tabular}{ccc}
\hline Software and processes & Listed software and processes & \% \\
\hline BIM Software Platforms* & 9 & $50 \%$ \\
Revit $^{\circledR}$ & 6 & $33 \%$ \\
Sketchup $^{\circledR * *}$ & 2 & $11 \%$ \\
ArchiCAD $^{\circledR}$ & 2 & $11 \%$ \\
Chief Architect $^{\circledR}$ & 2 & $11 \%$ \\
AutoCAD $^{\circledR * *}$ & 1 & $6 \%$ \\
Vectorworks $^{\circledR}$ & 1 & $6 \%$ \\
SolidBuilder & \\
Hired experienced employees & 10 & $56 \%$ \\
Trained current employees $_{\text {Implementation Process* }}$ & 7 & $39 \%$ \\
Self-led education & 4 & $22 \%$ \\
Hired experienced employees & 1 & $6 \%$ \\
\hline * Some of the 18 total Participants selected multiple software platforms & \\
\hline * It is recognized that these platforms alone may not constitute BIM. However, in most cases, they were used \\
in conjunction with other platforms increasing the Information component that is crucial for BIM. \\
\hline
\end{tabular}




\subsubsection{BIM Uses, Benefits, and Challenges}

The participants were then asked to identify how BIM was used in their company as well as any benefits and/or challenges/issues they found as a result of its use. The purpose of these questions was simply to populate lists for use in the subsequent questionnaires, but some valuable analysis was performed on this primarily qualitative data.

The following uses were identified:

- Marketing

- Design and visualization

- Field management/corrections

- Creation of construction documents

- Design coordination and/or clash detection

- Scheduling

- Quantity take-offs or estimating

The following benefits were identified:

- Plan accuracy

- Client visualization

- Quicker, more accurate quantity take-off's or estimating

- Improved client communication

- Improved communication with/between trades

- Improved scheduling effectiveness

- Early identification of design errors

- Improved marketing materials (i.e. renderings)

- Ease of plan revisions

- Ability to show plan from different angles

The following challenges or issues were identified:

- High software costs

- Steep learning curve when training employees

- Time-consuming to create and maintain models correctly

- Overabundance of information can overwhelm or confuse clients

- Lots of training is required to maintain effectiveness

- Computer hardware requirements

- Different BIM platforms or versions are often incompatible

- BIM software seems catered to commercial construction

- Software platforms require updates for continued use

- Difficult to find qualified, experienced employees 


\subsubsection{Questionnaire 1 Cross-Tabulation Analysis}

Cross-tabulations were performed that compared the demographic data to the uses, benefits, and challenges. Because participants were asked to identify the uses, benefits, and challenges, they had to be codified to be used in subsequent questionnaires. After all the responses were codified, the researcher counted which uses, benefits and challenges were listed under each demographic sector in which each member fell. The researcher then compared each demographic (Number of employees, Number of homes built per year and Average Sale Price per Home) individually with the uses, benefits, and challenges identified.

\subsubsection{Number of Employees}

The number of employees data indicated that within the 1-10 employee group, of which there were 13 members, the most common use was quantity take-offs with $46 \%$ percent of the participants listing that as a use. Quantity take-offs was followed by design and visualization and field management/corrections with $31 \%$ and $23 \%$, respectively, of members listing them. The 11-25 employee group, consisting of three members, reported that the most common uses were design and visualization and scheduling each with $67 \%$ of the members listing them as common uses in their company. They were followed by design coordination and/or clash detection and quantity take-offs each with 33\%, respectively. The 26-50 employee group, consisting of one member, reported that the most common uses of BIM were design and visualization and the creation of construction documents. The 51+ employee group, consisting of one member, listed design, and visualization, design coordination and/or clash detection, and quantity take-offs as the main uses. 
Table 4.3: BIM Uses Organized by Number of Employees

\begin{tabular}{|c|c|c|}
\hline Number of Employees & $\begin{array}{c}\text { Listed Uses of } \\
\text { BIM }\end{array}$ & $\%$ \\
\hline $1-10$ & \multicolumn{2}{|c|}{13 Total Respondents } \\
\hline Quantity take-offs & 6 & $46 \%$ \\
\hline Design and visualization & 4 & $31 \%$ \\
\hline Field management/corrections & 3 & $23 \%$ \\
\hline Marketing & 2 & $15 \%$ \\
\hline Creation of construction documents & 2 & $15 \%$ \\
\hline Design coordination and/or clash detection & 2 & $15 \%$ \\
\hline Scheduling & 2 & $15 \%$ \\
\hline $11-25$ & \multicolumn{2}{|c|}{3 Total Respondents } \\
\hline Design and visualization & 2 & $67 \%$ \\
\hline Scheduling & 2 & $67 \%$ \\
\hline Design coordination and/or clash detection & 1 & $33 \%$ \\
\hline Quantity take-offs & 1 & $33 \%$ \\
\hline 26-50 & \multicolumn{2}{|c|}{1 Total Respondent } \\
\hline Design and visualization & 1 & $100 \%$ \\
\hline Creation of construction documents & 1 & $100 \%$ \\
\hline $51+$ & \multicolumn{2}{|c|}{1 Total Respondent } \\
\hline Design and visualization & 1 & $100 \%$ \\
\hline Design coordination and/or clash detection & 1 & $100 \%$ \\
\hline Quantity take-offs & 1 & $100 \%$ \\
\hline
\end{tabular}

The number of employees data also indicated that within the 1-10 employee group, the most common benefit of BIM was client visualization with $46 \%$ of the participants listing it as a benefit. Client visualization was followed by plan accuracy, improved client communication and improved communication with/between trades, each with $31 \%$ of members listing it as a benefit. The only benefits listed by the 11-25 employee group were plan accuracy and quicker, more accurate quantity take-offs. The benefits listed by the 26-50 group, which consisted of one member, were plan accuracy, client visualization, improved communication with/between trades and the ease of plan revisions. The 51+ employee group, also consisting of one member, reported that their benefits were client visualization, quicker, more accurate quantity take-offs, improved client communication and early identification of design errors. 
Table 4.4: BIM Benefits Organized by Number of Employees

\begin{tabular}{llcc}
\hline Number of Employees & $\begin{array}{c}\text { Listed Benefits of } \\
\text { BIM }\end{array}$ & \% \\
\hline $\mathbf{1 - 1 0}$ & & $\mathbf{1 3}$ Total Respondents \\
& Client visualization & 6 & $46 \%$ \\
& Plan accuracy & 4 & $31 \%$ \\
& Improved client communication & 4 & $31 \%$ \\
& Improved communication with/between trades & 4 & $31 \%$ \\
& Quicker, more accurate quantity take-off's or estimating & 3 & $23 \%$ \\
& Early identification of design errors & 3 & $23 \%$ \\
& Improves scheduling effectiveness & 1 & $8 \%$ \\
& Improved marketing materials (i.e. renderings) & 1 & $8 \%$ \\
& Ability to show plan from different angles & 1 & $8 \%$ \\
$\mathbf{1 1 - 2 5}$ & & $\mathbf{3}$ Total Respondents \\
& Plan accuracy & 1 & $33 \%$ \\
& Quicker, more accurate quantity take-off's or estimating & 1 & $33 \%$ \\
$\mathbf{2 6 - 5 0}$ & & $\mathbf{1}$ Total Respondent \\
& Plan accuracy & 1 & $100 \%$ \\
& Client visualization & 1 & $100 \%$ \\
& Improved communication with/between trades & 1 & $100 \%$ \\
& Ease of plan revisions & 1 & $100 \%$ \\
$\mathbf{5 1 +}$ & & 1 & $100 \%$ \\
& Client visualization & 1 & $100 \%$ \\
& Quicker, more accurate quantity take-off's or estimating & 1 & $100 \%$ \\
Improved client communication & 1 & 1 \\
Early identification of design errors & 1 & \\
\hline
\end{tabular}

The cross-tabulation data for this demographic series indicated that within the 1-10 employee group, consisting of 13 members, the most common challenge was that it is timeconsuming to create and maintain models correctly with $46 \%$ if participants listing it as a challenge. The rest of the challenges identified were relatively uniform in their distribution among the responses. The 11-25 employee group identified the steep learning curve when training employees and the extensive amounts of training required to maintain effectiveness as there most common challenges. The 26-50 employee group listed that BIM software seems catered to commercial construction and software platforms require updates for continued use as 
their most common challenges. The member that constituted 51+ employee group reported that the steep learning curve when training employees, the amount of training required to maintain effectiveness, and different BIM platforms or versions are often incompatible were their most common challenges.

Table 4.5: BIM Challenges Organized by Number of Employees

\begin{tabular}{|c|c|c|c|}
\hline \multicolumn{2}{|c|}{ Number of Employees } & \multirow{2}{*}{\multicolumn{2}{|c|}{$\begin{array}{c}\begin{array}{l}\text { Listed Challenges of } \\
\text { BIM }\end{array} \\
13 \text { Total Respondents }\end{array}$}} \\
\hline 1-10 & & & \\
\hline & Time-consuming to create and maintain models correctly & 6 & $46 \%$ \\
\hline & High software costs & 1 & $8 \%$ \\
\hline & Steep learning curve when training employees & 1 & $8 \%$ \\
\hline & Overabundance of information can overwhelm or confuse clients & 1 & $8 \%$ \\
\hline & Lots of training is required to maintain effectiveness & 1 & $8 \%$ \\
\hline & Computer hardware needs to be substantial & 1 & $8 \%$ \\
\hline & Difficult to find qualified, experienced employees & 1 & $8 \%$ \\
\hline \multirow[t]{3}{*}{$11-25$} & & 3 Total Respondent & \\
\hline & Steep learning curve when training employees & 1 & $33 \%$ \\
\hline & Lots of training is required to maintain effectiveness & 1 & $33 \%$ \\
\hline \multirow[t]{3}{*}{ 26-50 } & & 1 Total Responden & \\
\hline & BIM software seems catered to commercial construction & 1 & $100 \%$ \\
\hline & Software platforms require updates for continued use & 1 & $100 \%$ \\
\hline \multirow[t]{4}{*}{$51+$} & & 1 Total Responden & \\
\hline & Steep learning curve when training employees & 1 & $100 \%$ \\
\hline & Time-consuming to create and maintain models correctly & 1 & $100 \%$ \\
\hline & Different BIM platforms or versions are often incompatible & 1 & $100 \%$ \\
\hline
\end{tabular}

\subsubsection{Number of Homes}

The number of homes built per year data indicates that the $0-10$ homes group, consisting of 12 members, reported that quantity take-offs and design and visualization are the top uses with $50 \%$ and $33 \%$ of members listing them. The 11-30 homes group, consisting of five members, listed design and visualization and field management/corrections with $60 \%$ and $40 \%$ of the 
members listing each. The 31-60 homes group did not have any participants and, therefore, there is no data for this group. The $61+$ homes group, consisting of one member, listed their main uses as design and visualization, the creation of construction documents, design coordination and/or clash detection, and quantity take-offs.

Table 4.6: BIM Uses Organized by Number of Homes

\begin{tabular}{llcc}
\hline Number of Homes & Listed Uses of BIM & \% \\
\hline $\mathbf{0 - 1 0}$ & & $\mathbf{1 2}$ Total Respondents \\
& Quantity take-offs & 6 & $50 \%$ \\
& Design and visualization & 4 & $33 \%$ \\
& Design coordination and/or clash detection & 3 & $25 \%$ \\
& Scheduling & 3 & $25 \%$ \\
& Marketing & 1 & $8 \%$ \\
& Field management/corrections & 1 & $8 \%$ \\
& Creation of construction documents & 1 & $8 \%$ \\
$\mathbf{1 1 - 3 0}$ & & $\mathbf{5}$ Total Respondents \\
& Design and visualization & 3 & $60 \%$ \\
& Field management/corrections & 2 & $40 \%$ \\
& Marketing & 1 & $20 \%$ \\
Creation of construction documents & 1 & $20 \%$ \\
Scheduling & 1 & $20 \%$ \\
Quantity take-offs & 1 & $20 \%$ \\
& & 1 & \\
$\mathbf{6 1 +}$ & Design and visualization & 1 & $100 \%$ \\
& Creation of construction documents & 1 & $100 \%$ \\
Design coordination and/or clash detection & $100 \%$ \\
Quantity take-offs & $100 \%$ \\
\hline
\end{tabular}

The benefits for this demographic group were defined as follows. The main benefits listed by the $0-10$ homes per year group were client visualization and improved client communication with 33\% each, followed by plan accuracy and quicker, more accurate quantity take-offs with $25 \%$ of the members listing them as benefits. The benefits were almost uniformly distributed among the 11-30 homes per year group. The 61+ homes group, consisting of one member, 
reported plan accuracy, client visualization, and quicker, more accurate quantity take-offs or estimating as their main benefits.

Table 4.7: BIM Benefits Organized by Number of Homes

\begin{tabular}{lcc}
\hline Number of Homes & Listed Benefits of & BIM \\
\hline $\mathbf{0 - 1 0}$ & $\mathbf{1 2}$ Total Respondents \\
$\quad$ Client visualization & 4 & $33 \%$ \\
$\quad$ Improved client communication & 4 & $33 \%$ \\
$\quad$ Plan accuracy & 3 & $25 \%$ \\
$\quad$ Quicker, more accurate quantity take-off's or estimating & 3 & $25 \%$ \\
$\quad$ Improved communication with/between trades & 2 & $17 \%$ \\
$\quad$ Improves scheduling effectiveness & 2 & $17 \%$ \\
Early identification of design errors & 2 & $17 \%$ \\
$\quad$ Improved marketing materials (i.e. renderings) & 1 & $8 \%$ \\
$\quad$ Ability to show plan from different angles & 1 & $8 \%$ \\
$\mathbf{1 1 - 3 0}$ & $\mathbf{5}$ Total Respondents \\
Client visualization & 2 & $40 \%$ \\
Plan accuracy & 1 & $20 \%$ \\
Quicker, more accurate quantity take-off's or estimating & 1 & $20 \%$ \\
Improved client communication & 1 & $20 \%$ \\
$\quad$ Improved communication with/between trades & 1 & $20 \%$ \\
Improves scheduling effectiveness & 1 & $20 \%$ \\
Early identification of design errors & 1 & $20 \%$ \\
Improved marketing materials (i.e. renderings) & 1 & $20 \%$ \\
Ease of plan revisions & 1 & $20 \%$ \\
$\mathbf{6 1 +}$ & 1 Total Respondent \\
Plan accuracy & 1 & $100 \%$ \\
Client visualization & 1 & $100 \%$ \\
Quicker, more accurate quantity take-off's or estimating & 1 & $100 \%$ \\
\hline
\end{tabular}

The challenges reported for this demographic group were reported by the $0-10$ homes per year group to be that it is time-consuming to create and maintain models correctly and that there is a steep learning curve when training employees with $42 \%$ and $33 \%$, respectively, of the members listing them as challenges. The 11-30 homes per year group listed that it is timeconsuming to create and maintain models correctly, computer hardware requirements can be 
substantial, BIM software seems catered to commercial construction and that it is difficult to find qualified, experienced employees as their main challenges. The 61+ homes per year group listed that it is time-consuming to create and maintain models correctly as their main challenge.

Table 4.8: BIM Challenges Organized by Number of Homes

\begin{tabular}{lcc}
\hline Number of Homes & $\begin{array}{c}\text { Listed Challenges of } \\
\text { BIM }\end{array}$ & $\mathbf{\%}$ \\
\hline $\mathbf{0 - 1 0}$ & $\mathbf{1 2}$ Total Respondents \\
Time-consuming to create and maintain models correctly & 5 & $42 \%$ \\
Steep learning curve when training employees & 4 & $33 \%$ \\
High software costs & 1 & $8 \%$ \\
Overabundance of information can overwhelm or confuse clients & 1 & $8 \%$ \\
Lots of training is required to maintain effectiveness & 1 & $8 \%$ \\
Different BIM platforms or versions are often incompatible & 1 & $8 \%$ \\
Difficult to find qualified, experienced employees & 1 & $8 \%$ \\
$\mathbf{1 1 - 3 0}$ & $\mathbf{5}$ Total Respondents \\
Time-consuming to create and maintain models correctly & 1 & $20 \%$ \\
Computer hardware needs to be substantial & 1 & $20 \%$ \\
BIM software seems catered to commercial construction & 1 & $20 \%$ \\
Software platforms require updates for continued use & 1 & $20 \%$ \\
Difficult to find qualified, experienced employees & 1 & $20 \%$ \\
$\mathbf{6 1 +}$ & $\mathbf{1}$ Total Respondent \\
$\quad$ Time-consuming to create and maintain models correctly & 1 & $100 \%$ \\
\hline
\end{tabular}

\subsubsection{Average Sale Price per Home}

The average sale price per home groups began with the $\$ 250,001-\$ 500,000$ group, consisting of seven members, who reported that their most common uses of BIM are design and visualization, field management/corrections, and quantity take-offs with $43 \%$ of members listing them. The $\$ 500,001-\$ 750,000$ group, consisting of three members, most commonly listed design and visualization as a use utilized by their company with two of the three members listing it. The $\$ 750,001-\$ 1,000,000$ group, consisting of two members, listed design and visualization and the creation of construction documents as uses. The $\$ 1,000,001+$ group was comprised of six 
members. The following uses were all listed by two of the members, which constituted the highest concentration of listings: design and visualization, design coordination and/or clash detection, scheduling, and quantity take-offs.

Table 4.9: BIM Uses Organized by Average Sale Price

\begin{tabular}{|c|c|c|}
\hline Average Sale Price & $\begin{array}{c}\text { Listed Uses of } \\
\text { BIM }\end{array}$ & $\%$ \\
\hline$\$ 250,001-\$ 500,000$ & \multicolumn{2}{|c|}{7 Total Respondents } \\
\hline Design and visualization & 3 & $43 \%$ \\
\hline Field management/corrections & 3 & $43 \%$ \\
\hline Quantity take-offs & 3 & $43 \%$ \\
\hline Marketing & 2 & $29 \%$ \\
\hline Creation of construction documents & 2 & $29 \%$ \\
\hline Design coordination and/or clash detection & 1 & $14 \%$ \\
\hline Scheduling & 1 & $14 \%$ \\
\hline$\$ 500,001-\$ 750,000$ & \multicolumn{2}{|c|}{3 Total Respondents } \\
\hline Design and visualization & 2 & $67 \%$ \\
\hline Marketing & 1 & $33 \%$ \\
\hline Field management/corrections & 1 & $33 \%$ \\
\hline Design coordination and/or clash detection & 1 & $33 \%$ \\
\hline Scheduling & 1 & $33 \%$ \\
\hline Quantity take-offs & 1 & $33 \%$ \\
\hline$\$ 750,001-\$ 1,000,000$ & \multicolumn{2}{|c|}{2 Total Respondents } \\
\hline Design and visualization & 1 & $50 \%$ \\
\hline Creation of construction documents & 1 & $50 \%$ \\
\hline$\$ 1,000,001+$ & \multicolumn{2}{|c|}{6 Total Respondents } \\
\hline Design and visualization & 2 & $33 \%$ \\
\hline Design coordination and/or clash detection & 2 & $33 \%$ \\
\hline Scheduling & 2 & $33 \%$ \\
\hline Quantity take-offs & 2 & $33 \%$ \\
\hline Field management/corrections & 1 & $17 \%$ \\
\hline
\end{tabular}

The most commonly listed benefits by the $\$ 250,001-\$ 500,000$ group were plan accuracy and client visualization with $43 \%$ of members listing them. The $\$ 500,001-\$ 750,000$ group listed client visualization and improved client communication, each with two of the three members listing them, as their most common benefits. The $\$ 750,001-\$ 1,000,000$ group reported that their 
most common benefits were plan accuracy, client visualization, improved communication

with/between trades, the ease of plan revisions, and the ability to show the plan from different

angles. The \$1,000,001+ group listed client visualization and improved client communication as

their most common benefits.

Table 4.10: BIM Benefits Organized by Average Sale Price

\begin{tabular}{lcc}
\hline Average Sale Price & Listed Benefits of & BIM \\
\hline $\mathbf{\$ 2 5 0 , 0 0 1 - \$ 5 0 0 , 0 0 0}$ & $\mathbf{7}$ Total Respondents \\
Plan accuracy & 3 & $43 \%$ \\
Client visualization & 3 & $43 \%$ \\
Quicker, more accurate quantity take-off's or estimating & 2 & $29 \%$ \\
Improved client communication & 2 & $29 \%$ \\
Improved communication with/between trades & 2 & $29 \%$ \\
Improves scheduling effectiveness & 1 & $14 \%$ \\
Early identification of design errors & 1 & $14 \%$ \\
$\mathbf{\$ 5 0 0 , 0 0 1 - \$ 7 5 0 , 0 0 0}$ & $\mathbf{3}$ Total Respondents \\
Client visualization & 2 & $67 \%$ \\
Improved client communication & 2 & $67 \%$ \\
Quicker, more accurate quantity take-off's or estimating & 1 & $33 \%$ \\
Improved communication with/between trades & 1 & $33 \%$ \\
Early identification of design errors & 1 & $33 \%$ \\
Improved marketing materials (i.e. renderings) & 1 & $33 \%$ \\
$\mathbf{\$ 7 5 0 , 0 0 1 - \$ 1 , 0 0 0 , 0 0 0}$ & $\mathbf{2}$ Total Respondents \\
Plan accuracy & 1 & $50 \%$ \\
Client visualization & 1 & $50 \%$ \\
Improved communication with/between trades & 1 & $50 \%$ \\
Ease of plan revisions & 1 & $50 \%$ \\
Ability to show plan from different angles & 1 & $50 \%$ \\
$\mathbf{\$ 1 , 0 0 0 , 0 0 1 +}$ & $\mathbf{6}$ Total Respondents \\
Client visualization & 2 & $33 \%$ \\
Improved client communication & 2 & $33 \%$ \\
Improved communication with/between trades & 1 & $17 \%$ \\
Quicker, more accurate quantity take-off's or estimating & 1 & $17 \%$ \\
\hline
\end{tabular}

The challenges identified by the $\$ 250,001-\$ 500,000$ group were that it is time-consuming to create and maintain models correctly with $57 \%$ of the members listing it. The $\$ 500,001-$ $\$ 750,000$ group had no apparent commonly listed challenges. The \$750,001-\$1,000,000 group listed that it is time-consuming to create and maintain the models correctly, BIM software seems catered to commercial construction, and software platforms require updates for continued use as 
their most common challenges. The most commonly listed challenge by the $\$ 1,000,001+$ group was the steep learning curve when training employees.

Table 4.11: BIM Challenges Organized by Average Sale Price

\begin{tabular}{|c|c|c|}
\hline Average Sale Price & $\begin{array}{c}\text { Listed Challenges of } \\
\text { BIM }\end{array}$ & $\%$ \\
\hline$\$ 250,001-\$ 500,000$ & \multicolumn{2}{|c|}{7 Total Respondents } \\
\hline Time-consuming to create and maintain models correctly & 4 & $57 \%$ \\
\hline Steep learning curve when training employees & 2 & $29 \%$ \\
\hline High software costs & 1 & $14 \%$ \\
\hline Overabundance of information can overwhelm or confuse clients & 1 & $14 \%$ \\
\hline Difficult to find qualified, experienced employees & 1 & $14 \%$ \\
\hline$\$ 500,001-\$ 750,000$ & \multicolumn{2}{|c|}{3 Total Respondents } \\
\hline Steep learning curve when training employees & 1 & $33 \%$ \\
\hline Time-consuming to create and maintain models correctly & 1 & $33 \%$ \\
\hline Lots of training is required to maintain effectiveness & 1 & $33 \%$ \\
\hline Computer hardware needs to be substantial & 1 & $33 \%$ \\
\hline BIM software seems catered to commercial construction & 1 & $33 \%$ \\
\hline$\$ 750,001-\$ 1,000,000$ & \multicolumn{2}{|c|}{2 Total Respondents } \\
\hline Time-consuming to create and maintain models correctly & 1 & $50 \%$ \\
\hline BIM software seems catered to commercial construction & 1 & $50 \%$ \\
\hline Software platforms require updates for continued use & 1 & $50 \%$ \\
\hline$\$ 1,000,001+$ & \multicolumn{2}{|c|}{6 Total Respondents } \\
\hline Steep learning curve when training employees & 3 & $50 \%$ \\
\hline Time-consuming to create and maintain models correctly & 1 & $17 \%$ \\
\hline Lots of training is required to maintain effectiveness & 1 & $17 \%$ \\
\hline Different BIM platforms or versions are often incompatible & 1 & $17 \%$ \\
\hline Software platforms require updates for continued use & 1 & $17 \%$ \\
\hline Difficult to find qualified, experienced employees & 1 & $17 \%$ \\
\hline
\end{tabular}

\subsection{Questionnaire 2 Design}

Questionnaire 2 was drafted and designed from the responses obtained in questionnaire 1. Fifteen responses were received for the second questionnaire. The participants for this questionnaire consisted of eight owners, three BIM managers, two designers and one project manager. The participants were asked to rank the data obtained previously. The questions for this 
questionnaire were related to implementation processes, uses of BIM, benefits of BIM, and challenges associated with BIM use.

\subsubsection{Implementation Processes}

The panel members were asked to rank the implementation processes identified in questionnaire 1 according to the likelihood that they would use that process if they were to repeat the implementation process. The implementation processes were ranked on a 1-4 Likert scale where $1=$ most likely to use and $4=$ least likely to use. The rankings were then averaged to identify the process that was most likely to be used overall. These rankings can be found in Table 4.12 below.

Table 4.12: Implementation Processes Ranked in Questionnaire 2

\begin{tabular}{lc}
\hline Processes & $\begin{array}{c}\text { Average Ranking } \\
\text { (1=most likely to be used, }\end{array}$ \\
\hline Attended or watched training courses & 2.36 \\
Trained current employees & 2.43 \\
Self-led education & 2.64 \\
Hired experienced employees & 3.00 \\
\hline 15 Total Respondents & \\
\hline
\end{tabular}

According to this ranking, there is no one clear best process for implementation.

However, as indicated in Table 4.12, attending or watching training courses received the highest overall ranking. It is also important to note the difference between the implementation processes identified in questionnaire 1 and questionnaire 2. Questionnaire 1 identified hiring experienced employees as the most commonly used process, with $56 \%$ of participants listing it, and attending or watching training courses as the least utilized process, with $6 \%$ of participants listing it. Questionnaire 2, however, indicated that, while there was not a significant difference in ranking, 
watching or attending training courses was the process most likely to be used and hiring experienced employees was the least likely to be used if the implementation process was repeated.

\subsubsection{BIM Uses}

The participants were asked to identify the top three uses utilized in their company. They then ranked those top three uses. The most commonly selected uses were design and visualization, the creation of construction documents and quantity take-offs.

Table 4.13: BIM Most Common Uses Listed Questionnaire 2

\begin{tabular}{lcc}
\hline Uses & $\begin{array}{c}\text { Listed Uses of } \\
\text { BIM }\end{array}$ & $\mathbf{\%}$ \\
\hline Design and visualization & 13 & $93 \%$ \\
Creation of construction documents & 9 & $64 \%$ \\
Quantity take-offs & 6 & $43 \%$ \\
Marketing & 4 & $29 \%$ \\
Field management/corrections & 3 & $21 \%$ \\
Scheduling & 3 & $21 \%$ \\
Design coordination & 2 & $14 \%$ \\
\hline
\end{tabular}

After the participants identified their top three uses, they then ranked those top three uses based on most used to least used where $1=$ most used and $3=$ least used. The findings were weighted to identify the most utilized use. The following weights were used: $0=40,1=10,2=20$, $3=30$. If a use was not listed by a participant it received the greatest weight and had the most significant impact on the results. The results indicate that design and visualization is the most common use of BIM followed by the creation of construction documents. 
Table 4.14: BIM Most Commonly Utilized Uses Ranked in Questionnaire 2

\begin{tabular}{lc}
\hline Uses & Weighted Average* $^{*}$ \\
\hline Design and visualization & 2.30 \\
Creation of construction documents & 3.30 \\
Quantity take-offs & 4.70 \\
Marketing & 5.10 \\
Scheduling & 5.10 \\
Field management/corrections & 5.20 \\
Design coordination & 5.40
\end{tabular}

*Those uses with the lowest weighted average most commonly received the highest ranking. As the weighted average increased, the ranking received decreased.

Participants were also asked to identify any uses that their company either does not use or rarely utilize. They were able to select any use that applied. The least utilized use identified by this group was scheduling followed by design coordination.

Table 4.15: Rarely or Not Used BIM Uses*

\begin{tabular}{lcc}
\hline Uses & $\begin{array}{c}\text { Listed Uses Of } \\
\text { BIM }\end{array}$ & \% \\
\hline Scheduling & 7 & $50 \%$ \\
Design coordination & 5 & $36 \%$ \\
Marketing & 4 & $29 \%$ \\
Field management/corrections & 4 & $29 \%$ \\
Quantity take-offs & 3 & $21 \%$ \\
Creation of construction documents & 1 & $7 \%$ \\
\hline *According to this panel & & \\
\hline
\end{tabular}

The participants were asked what use was the most under-utilized use within their company. According to this panel, the most under-utilized use of BIM is quantity take-offs. 
Table 4.16: Most Under-Utilized Uses of BIM*

\begin{tabular}{lcc}
\hline Uses & $\begin{array}{c}\text { Listed Uses of } \\
\text { BIM }\end{array}$ & $\mathbf{\%}$ \\
\hline Quantity take-offs & 7 & $50 \%$ \\
Design coordination & 5 & $36 \%$ \\
Scheduling & 5 & $36 \%$ \\
Field management/corrections & 4 & $29 \%$ \\
Marketing & 3 & $21 \%$ \\
Creation of construction documents & 2 & $14 \%$ \\
Design and visualization & 1 & $7 \%$ \\
\hline * According to this Panel & & \\
\hline
\end{tabular}

\subsubsection{Benefits of BIM}

Similar to previous questions in this questionnaire, participants were asked to rank the benefits previously identified on a Likert scale where $1=$ most beneficial and $10=$ least beneficial . These rankings were averaged to find the lowest average ranking, thus identifying the most beneficial among all participants.

Table 4.17: BIM Benefits Ranked in Questionnaire 2

\begin{tabular}{lc}
\hline Benefits & $\begin{array}{c}\text { Average Ranking } \\
(1=\text { most beneficial, } 10=\text { =east beneficial })\end{array}$ \\
\hline Plan accuracy & 2.50 \\
Client visualization & 2.50 \\
Improved client communication & 4.40 \\
Ease of plan revisions & 5.10 \\
Early identification of design errors & 5.20 \\
Ability to show plan from different angles & 6.20 \\
Quicker, more accurate quantity take-off's or estimating & 6.50 \\
Improved communication with/between trades & 6.90 \\
Improves scheduling effectiveness & 7.50 \\
Improved marketing materials (i.e. renderings) & 8.10 \\
\hline
\end{tabular}


The benefits that proved to be the most beneficial to the panel members and their companies were plan accuracy and client visualization.

\subsubsection{Challenges Associated with BIM Use}

The participants were similarly asked to rank the challenges associated with the use of BIM on a Likert scale where $1=$ most challenging and $10=$ least challenging.

Table 4.18: BIM Challenges Ranked in Questionnaire 2

\begin{tabular}{lc}
\hline Challenges & $\begin{array}{c}\text { Average Ranking } \\
(1=\text { most beneficial, 10 =least beneficial })\end{array}$ \\
\hline Steep learning curve when training employees & 3.30 \\
High software costs & 3.90 \\
Time-consuming to create and maintain models correctly & 4.00 \\
Lots of training is required to maintain effectiveness & 5.30 \\
Computer hardware requirements & 5.60 \\
Difficult to find qualified, experienced employees & 5.60 \\
BIM software seems catered to commercial construction & 6.00 \\
Overabundance of information can overwhelm or confuse clients & 6.90 \\
Different BIM platforms or versions are often incompatible & 6.90 \\
Software platforms require updates for continued use & 7.30 \\
\hline
\end{tabular}

The most common challenges associated with BIM use are the steep learning curve when training employees and the high software costs, followed very closely by how time-consuming it is to create and maintain models correctly.

\subsubsection{Questionnaire 2 Cross-Tabulation Analysis}

Similar to questionnaire 1 , the cross-tabulation analysis was performed comparing the ranking data obtained in questionnaire 2 and the demographic data obtained in questionnaire 1. 
The purpose of this analysis was to identify any trends within any given demographic and also to corroborate the data received in questionnaire 1 . The cross-tabulations for this questionnaire compare the same sets of data as the previous cross-tabulations, namely, the average sale price per home, number of employees, and number of homes built per year with the ranking data relating to the uses, benefits, and challenges identified by the panel in the previous questionnaire. The uses data was analyzed according to the number of times a use was listed by the panel while the benefits and challenges rankings data was analyzed using an average ranking.

\subsubsection{Number of Employees: Questionnaire 2}

The panel members belonging to the 1-10 employee group, consisting of 11 members, listed design and visualization most often as one of their most common uses of BIM, with 10 of 11 participants listing it as a common use. This was followed by the creation of construction documents, with seven of eleven participants listing it. Design coordination and/or clash detection and scheduling received the fewest listings within this group, indicating that these are the least used uses by this demographic. The panel members in the 11-25 employee group, consisting of two members, indicated that design and visualization, as well as scheduling, were the most common uses with each of the two members listing them. These members each listed one other use. Marketing, field management/corrections, and design coordination and/or clash detection were not listed by this group. The 26-50 employee group, which consisted of only one member, selected as their top three uses the creation of construction documents, design and visualization, and marketing. They were also ranked in the order listed here. This group, however, did not list field management/corrections, design coordination and/or clash detection, scheduling, or quantity take-offs. 
Table 4.19: Most Common BIM Uses Organized by Number of Employees

\begin{tabular}{llcc}
\hline \multirow{2}{*}{ Number of Employees } & \multicolumn{2}{c}{ Listed Uses of } & BIM \\
\hline $\mathbf{1 - 1 0}$ & & $\mathbf{1 1}$ Total Respondents \\
& Design and visualization & 10 & $91 \%$ \\
& Creation of construction documents & 7 & $64 \%$ \\
& Quantity take-offs & 5 & $45 \%$ \\
& Marketing & 3 & $27 \%$ \\
& Field management/corrections & 3 & $27 \%$ \\
& Design coordination and/or clash detection & 2 & $18 \%$ \\
& Scheduling & 1 & $9 \%$ \\
$\mathbf{1 1 - 2 5}$ & & $\mathbf{2}$ Total Respondents \\
& Design and visualization & 2 & $100 \%$ \\
& Scheduling & 2 & $100 \%$ \\
& Creation of construction documents & 1 & $50 \%$ \\
$\mathbf{2 0 6 - 5 0}$ & Quantity take-offs & 1 & $50 \%$ \\
& & $\mathbf{1}$ & Total Respondent \\
& Marketing & 1 & $100 \%$ \\
& Design and visualization & 1 & $100 \%$ \\
& Creation of construction documents & 1 & $100 \%$ \\
\hline
\end{tabular}

The benefits rankings for the 1-10 employee group indicated that the benefit that was most beneficial to this group was client visualizations followed by plan accuracy. The average ranking of client visualization was 2.36 and plan accuracy was 2.64 . This group also ranked improved marketing materials and improved scheduling effectiveness as the least beneficial. The 11-25 employee ranked plan accuracy as their top benefit, with an average ranking of 2.5 , followed by client visualization and the improvement of scheduling effectiveness, each with an average ranking of 3 out of 10 with 1 being the highest. This group ranked early identification of design errors and improved marketing materials as the least beneficial. The top three benefits ranked, in the following order, by the 26-50 group, were plan accuracy, ease of plan revisions, and client visualization. This group ranked quicker, more accurate quantity take-offs and improved scheduling effectiveness as the least beneficial. 
Table 4.20: Ranked BIM Benefits Organized by Number of Employees

\begin{tabular}{|c|c|c|}
\hline \multicolumn{2}{|c|}{ Number of Employees } & \multirow{2}{*}{$\begin{array}{c}\text { Average Ranking } \\
(1=\text { most beneficial, } 10=\text { least beneficial }) \\
11 \text { Total Respondents }\end{array}$} \\
\hline 1-10 & & \\
\hline & Client visualization & 2.36 \\
\hline & Plan accuracy & 2.64 \\
\hline & Improved client communication & 4.36 \\
\hline & Early identification of design errors & 4.82 \\
\hline & Ease of plan revisions & 5.09 \\
\hline & Ability to show plan from different angles & 6.27 \\
\hline & Quicker, more accurate quantity take-off's or estimating & 6.45 \\
\hline & Improved communication with/between trades & 7.00 \\
\hline & Improved marketing materials (i.e. renderings) & 7.91 \\
\hline & Improves scheduling effectiveness & 8.09 \\
\hline \multirow[t]{11}{*}{ 11-25 } & & 2 Total Respondents \\
\hline & Plan accuracy & 2.50 \\
\hline & Client visualization & 3.00 \\
\hline & Improves scheduling effectiveness & 3.00 \\
\hline & Improved client communication & 5.00 \\
\hline & Quicker, more accurate quantity take-off's or estimating & 5.50 \\
\hline & Improved communication with/between trades & 6.00 \\
\hline & Ability to show plan from different angles & 6.00 \\
\hline & Ease of plan revisions & 7.00 \\
\hline & Early identification of design errors & 7.50 \\
\hline & Improved marketing materials (i.e. renderings) & 9.50 \\
\hline \multirow[t]{11}{*}{ 26-50 } & & 1 Total Respondent \\
\hline & Plan accuracy & 1.00 \\
\hline & Ease of plan revisions & 2.00 \\
\hline & Client visualization & 3.00 \\
\hline & Improved client communication & 4.00 \\
\hline & Early identification of design errors & 5.00 \\
\hline & Ability to show plan from different angles & 6.00 \\
\hline & Improved marketing materials (i.e. renderings) & 7.00 \\
\hline & Improved communication with/between trades & 8.00 \\
\hline & Quicker, more accurate quantity take-off's or estimating & 9.00 \\
\hline & Improves scheduling effectiveness & 10.00 \\
\hline
\end{tabular}

The challenges ranking by the 1-10 employee group indicates that the greatest challenge identified by this group was high software costs with an average ranking of 3.82, followed by how time-consuming it is to create and maintain models correctly with an average ranking of 3.91. This group identified different BIM platforms or versions are often incompatible and software platforms require updates for continued use as their least difficult challenges. The most difficult challenges identified by the 11-25 employee group were the steep learning curve when training employees and the time-consuming nature of creating and maintaining models correctly 
with average rankings of 1 and 2.5 respectively. This group also ranked overabundance of information can overwhelm or confuse clients and software platforms require updates for continued use as their least difficult challenges. The top three challenges ranked, in the following order, by the 26-50 employee group were high software cost, the steep learning curve when training employees, and the computer hardware requirements. This group ranked lots of training is required to maintain effectiveness and overabundance of information can overwhelm or confuse clients as their least difficult challenges. These rankings were based on a 1-10 scale with one being the highest possible ranking.

Table 4.21: Ranked BIM Challenges Organized by Number of Employees

\begin{tabular}{|c|c|}
\hline Number of Employees & $\begin{array}{c}\text { Average Ranking } \\
(1=\text { most beneficial, } 10=\text { least beneficial }) \\
\end{array}$ \\
\hline $1-10$ & 11 Total Respondents \\
\hline High software costs & 3.82 \\
\hline Steep learning curve when training employees & 3.91 \\
\hline Time-consuming to create and maintain models correctly & 4.00 \\
\hline Lots of training is required to maintain effectiveness & 5.27 \\
\hline Computer hardware needs to be substantial & 5.64 \\
\hline Difficult to find qualified, experienced employees & 5.64 \\
\hline Overabundance of information can overwhelm or confuse clients & 6.36 \\
\hline BIM software seems catered to commercial construction & 6.36 \\
\hline Different BIM platforms or versions are often incompatible & 6.91 \\
\hline Software platforms require updates for continued use & 7.09 \\
\hline $11-25$ & 2 Total Respondents \\
\hline Steep learning curve when training employees & 1.00 \\
\hline Time-consuming to create and maintain models correctly & 2.50 \\
\hline Lots of training is required to maintain effectiveness & 3.50 \\
\hline BIM software seems catered to commercial construction & 5.50 \\
\hline High software costs & 6.00 \\
\hline Difficult to find qualified, experienced employees & 6.00 \\
\hline Computer hardware needs to be substantial & 7.00 \\
\hline Different BIM platforms or versions are often incompatible & 7.00 \\
\hline Overabundance of information can overwhelm or confuse clients & 8.00 \\
\hline Software platforms require updates for continued use & 8.50 \\
\hline 26-50 & 1 Total Respondent \\
\hline High software costs & 1.00 \\
\hline Steep learning curve when training employees & 2.00 \\
\hline Computer hardware needs to be substantial & 3.00 \\
\hline BIM software seems catered to commercial construction & 4.00 \\
\hline Difficult to find qualified, experienced employees & 5.00 \\
\hline Different BIM platforms or versions are often incompatible & 6.00 \\
\hline Time-consuming to create and maintain models correctly & 7.00 \\
\hline Software platforms require updates for continued use & 8.00 \\
\hline Lots of training is required to maintain effectiveness & 9.00 \\
\hline Overabundance of information can overwhelm or confuse clients & 10.00 \\
\hline
\end{tabular}




\subsubsection{Number of Homes: Questionnaire 2}

Within the number of homes demographic in questionnaire 2, data was received from all the same groups represented in questionnaire 1 . Nine responses were received from the $0-10$ homes group, four from the 11-30 homes group, none from the 31-60 homes group, and one from the $61+$ homes group. The data from these groups is summarized below.

The $0-10$ homes group identified their top three uses as design and visualization, the creation of construction documents and quantity takeoffs. Eight out of the nine members of the group listed design and visualization as one of their most common uses. Six of the nine participants in this group listed creation of construction documents and five out of nine participants listed quantity take-offs. This group did not list marketing, indicating that it is not a common use within this demographic. The 11-30 homes group most commonly listed design and visualization, marketing, the creation of construction documents, and field management/corrections as their top three uses. Design and visualization was listed by all four participants in this group. Marketing was listed by three of the four participants. The creation of construction documents and field management/corrections were both listed by two of the four participants. This group did not list design coordination and/or clash detection or scheduling. The 61+ homes group, which only had one member responding, listed marketing, design and visualization, and the creation of construction documents. This member did not list field management/corrections, design coordination and/or clash detection, scheduling, or quantity take-offs. 
Table 4.22: Most Common BIM Uses Organized by Number of Homes

\begin{tabular}{|c|c|c|}
\hline Number of Homes & Listed Uses of BIM & $\%$ \\
\hline 0-10 & & 9 Total Respondents \\
\hline Design and visualization & 8 & $89 \%$ \\
\hline Creation of construction documents & 6 & $67 \%$ \\
\hline Quantity take-offs & 5 & $56 \%$ \\
\hline Design coordination and/or clash detection & 2 & $22 \%$ \\
\hline Field management/corrections & 1 & $11 \%$ \\
\hline Scheduling & 1 & $11 \%$ \\
\hline 11-30 & & 4 Total Respondents \\
\hline Design and visualization & 4 & $100 \%$ \\
\hline Marketing & 3 & $75 \%$ \\
\hline Field management/corrections & 2 & $50 \%$ \\
\hline Creation of construction documents & 2 & $50 \%$ \\
\hline Quantity take-offs & 1 & $25 \%$ \\
\hline $61+$ & & 1 Total Respondent \\
\hline Marketing & 1 & $100 \%$ \\
\hline Design and visualization & 1 & $100 \%$ \\
\hline Creation of construction documents & 1 & $100 \%$ \\
\hline
\end{tabular}

The 0-10 homes group identified client visualization, plan accuracy and improved client communication as their top three benefits. Those benefits each received average rankings of 2.33, 3.11, and 4.67 respectively. The 11-30 employee group ranked plan accuracy, client visualization, and improved client communication as their most beneficial with each receiving and an average ranking of 1.5, 2.25 and 3.25 respectively. The $61+$ homes group ranked, in this order, plan accuracy, ease of plan revisions, and early identification of design errors as providing the greatest benefit. 


\section{Table 4.23: Ranked BIM Benefits Organized by Number of Homes}

\begin{tabular}{|c|c|}
\hline Number of Homes & $\begin{array}{c}\text { Average Ranking } \\
(1=\text { most beneficial, } 10=\text { least beneficial })\end{array}$ \\
\hline $1-10$ & 9 Total Respondents \\
\hline Client visualization & 2.33 \\
\hline Plan accuracy & 3.11 \\
\hline Improved client communication & 4.67 \\
\hline Ease of plan revisions & 5.00 \\
\hline Early identification of design errors & 5.22 \\
\hline Ability to show plan from different angles & 5.89 \\
\hline Quicker, more accurate quantity take-off's or estimating & 6.00 \\
\hline Improves scheduling effectiveness & 6.89 \\
\hline Improved communication with/between trades & 7.11 \\
\hline Improved marketing materials (i.e. renderings) & 8.78 \\
\hline 11-30 & 4 Total Respondents \\
\hline Plan accuracy & 1.50 \\
\hline Client visualization & 2.25 \\
\hline Improved client communication & 3.25 \\
\hline Early identification of design errors & 5.75 \\
\hline Ability to show plan from different angles & 6.00 \\
\hline Improved communication with/between trades & 6.25 \\
\hline Ease of plan revisions & 6.25 \\
\hline Improved marketing materials (i.e. renderings) & 7.50 \\
\hline Quicker, more accurate quantity take-off's or estimating & 7.75 \\
\hline Improves scheduling effectiveness & 8.50 \\
\hline $61+$ & 1 Total Respondent \\
\hline Plan accuracy & 1.00 \\
\hline Ease of plan revisions & 2.00 \\
\hline Early identification of design errors & 3.00 \\
\hline Improved marketing materials (i.e. renderings) & 4.00 \\
\hline Client visualization & 5.00 \\
\hline Quicker, more accurate quantity take-off's or estimating & 6.00 \\
\hline Improved client communication & 7.00 \\
\hline Improved communication with/between trades & 8.00 \\
\hline Improves scheduling effectiveness & 9.00 \\
\hline Ability to show plan from different angles & 10.00 \\
\hline
\end{tabular}

The top three challenges identified by the $0-10$ homes group were the steep learning curve when training employees, high software costs, and the time-consuming nature of creating 
and maintaining models correctly which each received an average ranking of 2.67,4.00 and 4.11

respectively. The 11-30 homes group ranked high software costs as their top challenge with an

average ranking of 2.5 followed by computer hardware requirements with an average ranking of

4.25. The steep learning curve when training employees and the time-consuming nature of

creating and maintaining models correctly were next with average ranking of 4.5 each. The $61+$

homes group ranked, in this order, the time-consuming nature of creating and maintaining

models correctly, that different BIM platforms are often incompatible, and that extensive training

is required to maintain effectiveness as their top challenges.

Table 4.24: Challenges of BIM as Ranked and organized by Number of Homes

\begin{tabular}{|c|c|}
\hline Number of Homes & $\begin{array}{c}\text { Average Ranking } \\
(1=\text { most beneficial, } 10=\text { least beneficial })\end{array}$ \\
\hline $0-10$ & 9 Total Respondents \\
\hline Steep learning curve when training employees & 2.67 \\
\hline High software costs & 4.00 \\
\hline Time-consuming to create and maintain models correctly & 4.11 \\
\hline Lots of training is required to maintain effectiveness & 4.78 \\
\hline Difficult to find qualified, experienced employees & 5.11 \\
\hline BIM software seems catered to commercial construction & 6.33 \\
\hline Computer hardware needs to be substantial & 6.44 \\
\hline Overabundance of information can overwhelm or confuse clients & 7.00 \\
\hline Different BIM platforms or versions are often incompatible & 7.11 \\
\hline Software platforms require updates for continued use & 7.44 \\
\hline 11-30 & 4 Total Respondents \\
\hline High software costs & 2.50 \\
\hline Computer hardware needs to be substantial & 4.25 \\
\hline Steep learning curve when training employees & 4.50 \\
\hline Time-consuming to create and maintain models correctly & 4.50 \\
\hline BIM software seems catered to commercial construction & 5.50 \\
\hline Overabundance of information can overwhelm or confuse clients & 5.75 \\
\hline Difficult to find qualified, experienced employees & 6.00 \\
\hline Lots of training is required to maintain effectiveness & 7.00 \\
\hline Different BIM platforms or versions are often incompatible & 7.50 \\
\hline Software platforms require updates for continued use & 8.50 \\
\hline $61+$ & 1 Total Respondent \\
\hline Time-consuming to create and maintain models correctly & 1.00 \\
\hline Different BIM platforms or versions are often incompatible & 2.00 \\
\hline Lots of training is required to maintain effectiveness & 3.00 \\
\hline Computer hardware needs to be substantial & 4.00 \\
\hline Steep learning curve when training employees & 5.00 \\
\hline BIM software seems catered to commercial construction & 6.00 \\
\hline Software platforms require updates for continued use & 7.00 \\
\hline Difficult to find qualified, experienced employees & 8.00 \\
\hline High Software Costs & 9.00 \\
\hline Overabundance of information can overwhelm or confuse clients & 10.00 \\
\hline
\end{tabular}




\subsubsection{Average Sale Price: Questionnaire 2}

Responses were collected from all average sale price demographic groups represented in questionnaire 1. Seven responses were received from the $\$ 250,001-\$ 500,000$ group. Two responses were received from the $\$ 500,001-\$ 7500,000$ group. One response was received from the $\$ 750,001-\$ 1,000,000$ group. Four responses were received from the from the $\$ 1,000,001+$ group.

The \$250,001-\$500,000 group listed design and visualization and the creation of construction documents as their most common uses with six of seven participants listing each use followed by quantity take-offs with three listings. Marketing, field management/corrections, design coordination and/or clash detection, and scheduling were the least commonly listed uses. The \$500-001-\$750,000 group listed design and visualization as their top use with both participants in the group listing it as a top use. This group also listed marketing, field management/corrections, the creation of construction documents, and quantity take-offs as uses, each with one listing. This group, however, did not list design coordination and/or clash detection, or scheduling within their most common uses. The $\$ 750,001-\$ 1,000,000$ group listed marketing, design and visualization, and the creation of construction documents as their top three uses. This group did not list field management/corrections, design coordination and/or clash detection, scheduling, or quantity take-offs. The $\$ 1,000,001+$ group most commonly listed design and visualization, and quantity take-offs as their top uses with design and visualization receiving four of four listings and quantity take-offs receiving two of four listings. The rest of the uses each received one listing which were the least commonly listed uses. 
Table 4.25: Most Common BIM Uses Organized by Average Sale Price

\begin{tabular}{|c|c|c|}
\hline Average Sale Price & Listed Uses of BIM & $\%$ \\
\hline$\$ 250,001-\$ 500,000$ & 7 Total Respondents & \\
\hline Design and visualization & 6 & $86 \%$ \\
\hline Creation of construction documents & 6 & $86 \%$ \\
\hline Quantity take-offs & 3 & $43 \%$ \\
\hline Marketing & 1 & $14 \%$ \\
\hline Field management/corrections & 1 & $14 \%$ \\
\hline Design coordination and/or clash detection & 1 & $14 \%$ \\
\hline Scheduling & 1 & $14 \%$ \\
\hline$\$ 500,001-\$ 750,000$ & 2 Total Respondents & \\
\hline Design and visualization & 2 & $100 \%$ \\
\hline Marketing & 1 & $50 \%$ \\
\hline Field management/corrections & 1 & $50 \%$ \\
\hline Creation of construction documents & 1 & $50 \%$ \\
\hline Quantity take-offs & 1 & $50 \%$ \\
\hline$\$ 750,001-\$ 1,000,000$ & 1 Total Respondent & \\
\hline Marketing & 1 & $100 \%$ \\
\hline Design and visualization & 1 & $100 \%$ \\
\hline Creation of construction documents & 1 & $100 \%$ \\
\hline$\$ 1,000,001+$ & 4 Total Respondents & \\
\hline Design and visualization & 4 & $100 \%$ \\
\hline Quantity take-offs & 2 & $50 \%$ \\
\hline Marketing & 1 & $25 \%$ \\
\hline Field management/corrections & 1 & $25 \%$ \\
\hline Creation of construction documents & 1 & $25 \%$ \\
\hline Design coordination and/or clash detection & 1 & $25 \%$ \\
\hline Scheduling & 1 & $25 \%$ \\
\hline
\end{tabular}

The $\$ 250,001-\$ 500,000$ group ranked plan accuracy, which received an average ranking of 2.29, client visualization, which received an average ranking of 2.71, and ease of plan revisions, which received an average ranking of 3.43 , as their greatest benefits. The $\$ 500$-001$\$ 750,000$ group ranked plan accuracy and client visualization as their top benefits each with an average ranking of 2.00 , followed by improved client communication with an average ranking of 3.00. The $\$ 750,001-\$ 1,000,000$ group ranked, in the following order, plan accuracy, ease of plan revisions, and client visualization as their top three benefits. The $\$ 1,000,001+$ group ranked 
client visualization, which received an average ranking of 2.25 , plan accuracy, which received an average ranking of 3.50, improved client communication and improved scheduling effectiveness, which each received rankings of 4.50, as their greatest benefits.

Table 4.26: Benefits of BIM as Ranked and organized by Average Sale Price

\begin{tabular}{|c|c|}
\hline Average Sale Price & $\begin{array}{c}\text { Average Ranking } \\
(1=\text { most beneficial, } 10=\text { least beneficial })\end{array}$ \\
\hline$\$ 250,001-\$ 500,000$ & 7 Total Respondents \\
\hline Plan accuracy & 2.29 \\
\hline Client visualization & 2.71 \\
\hline Ease of plan revisions & 3.43 \\
\hline Early identification of design errors & 4.71 \\
\hline Improved client communication & 4.86 \\
\hline Ability to show plan from different angles & 6.29 \\
\hline Quicker, more accurate quantity take-off's or estimating & 6.57 \\
\hline Improved marketing materials (i.e. renderings) & 7.71 \\
\hline Improved communication with/between trades & 8.00 \\
\hline Improves scheduling effectiveness & 8.43 \\
\hline$\$ 500,001-\$ 750,000$ & 2 Total Respondents \\
\hline Plan accuracy & 2.00 \\
\hline Client visualization & 2.00 \\
\hline Improved client communication & 3.00 \\
\hline Early identification of design errors & 5.50 \\
\hline Quicker, more accurate quantity take-off's or estimating & 6.00 \\
\hline Improved communication with/between trades & 6.00 \\
\hline Ease of plan revisions & 7.00 \\
\hline Ability to show plan from different angles & 7.00 \\
\hline Improved marketing materials (i.e. renderings) & 7.50 \\
\hline Improves scheduling effectiveness & 9.00 \\
\hline$\$ 750,001-\$ 1,000,000$ & 1 Total Respondent \\
\hline Plan accuracy & 1.00 \\
\hline Ease of plan revisions & 2.00 \\
\hline Client visualization & 3.00 \\
\hline Improved client communication & 4.00 \\
\hline Early identification of design errors & 5.00 \\
\hline Ability to show plan from different angles & 6.00 \\
\hline Improved marketing materials (i.e. renderings) & 7.00 \\
\hline Improved communication with/between trades & 8.00 \\
\hline Quicker, more accurate quantity take-off's or estimating & 9.00 \\
\hline Improves scheduling effectiveness & 10.00 \\
\hline$\$ 1,000,001+$ & 4 Total Respondents \\
\hline Client visualization & 2.25 \\
\hline Plan accuracy & 3.50 \\
\hline Improved client communication & 4.50 \\
\hline Improves scheduling effectiveness & 4.50 \\
\hline Improved communication with/between trades & 5.25 \\
\hline Ability to show plan from different angles & 5.75 \\
\hline Quicker, more accurate quantity take-off's or estimating & 6.00 \\
\hline Early identification of design errors & 6.00 \\
\hline Ease of plan revisions & 8.00 \\
\hline Improved marketing materials (i.e. renderings) & 9.25 \\
\hline
\end{tabular}


The \$250,001-\$500,000 group ranked the steep learning curve when training employees, which received an average ranking of 3.14, the time-consuming nature of creating and maintaining models correctly, which received an average ranking of 3.86, and high software costs, which received an average ranking of 4.14 , as their greatest challenges. This group also ranked Software platforms require updates for continued use and BIM software seems catered to commercial construction as their least difficult challenges. The $\$ 500-001-\$ 750,000$ group ranked the overabundance of information that confuses clients, which received an average ranking of 2.00, high software costs, which received an average ranking of 3.50, the time-consuming nature of creating and maintaining models correctly and computer hardware requirements, each with an average ranking of 5.00, as their greatest challenges. This group ranked different BIM platforms or versions are often incompatible and difficult to find qualified, experienced employees as their least difficult challenges. The $\$ 750,001-\$ 1,000,000$ group ranked, in the following order, high software costs, the steep learning curve when training employees, and computer hardware requirements as their greatest challenges. This member ranked lots of training is required to maintain effectiveness and overabundance of information can overwhelm or confuse clients as their least difficult challenge. The $\$ 1,000,001+$ group ranked the steep learning curve when training employees and the time-consuming nature of creating and maintaining the model correctly, which each received an average ranking of 3.00 , the difficulty of finding qualified, experienced employees, which received an average ranking of 4.25, and high software costs, which received an average ranking of 4.50 , as their greatest challenges. This group also ranked software platforms require updates for continued use and overabundance of information can overwhelm or confuse clients as their least difficult challenges. 
Table 4.27: Ranked BIM Challenges Organized by Average Sale Price

\begin{tabular}{|c|c|}
\hline Average Sale Price & $\begin{array}{c}\text { Average Ranking } \\
(1=\text { most beneficial, } 10=\text { least beneficial })\end{array}$ \\
\hline$\$ 250,001-\$ 500,000$ & 7 Total Respondents \\
\hline Steep learning curve when training employees & 3.14 \\
\hline Time-consuming to create and maintain models correctly & 3.86 \\
\hline High software costs & 4.14 \\
\hline Lots of training is required to maintain effectiveness & 4.57 \\
\hline Difficult to find qualified, experienced employees & 5.71 \\
\hline Different BIM platforms or versions are often incompatible & 6.29 \\
\hline Overabundance of information can overwhelm or confuse clients & 6.71 \\
\hline Computer hardware needs to be substantial & 6.71 \\
\hline Software platforms require updates for continued use & 6.86 \\
\hline BIM software seems catered to commercial construction & 7.00 \\
\hline$\$ 500,001-\$ 750,000$ & 2 Total Respondents \\
\hline Overabundance of information can overwhelm or confuse clients & 2.00 \\
\hline High software costs & 3.50 \\
\hline Time-consuming to create and maintain models correctly & 5.00 \\
\hline Computer hardware needs to be substantial & 5.00 \\
\hline Steep learning curve when training employees & 5.50 \\
\hline BIM software seems catered to commercial construction & 5.50 \\
\hline Lots of training is required to maintain effectiveness & 6.50 \\
\hline Software platforms require updates for continued use & 6.50 \\
\hline Different BIM platforms or versions are often incompatible & 7.00 \\
\hline Difficult to find qualified, experienced employees & 8.50 \\
\hline$\$ 750,001-\$ 1,000,000$ & 1 Total Respondent \\
\hline High software costs & 1.00 \\
\hline Steep learning curve when training employees & 2.00 \\
\hline Computer hardware needs to be substantial & 3.00 \\
\hline BIM software seems catered to commercial construction & 4.00 \\
\hline Difficult to find qualified, experienced employees & 5.00 \\
\hline Different BIM platforms or versions are often incompatible & 6.00 \\
\hline Time-consuming to create and maintain models correctly & 7.00 \\
\hline Software platforms require updates for continued use & 8.00 \\
\hline Lots of training is required to maintain effectiveness & 9.00 \\
\hline Overabundance of information can overwhelm or confuse clients & 10.00 \\
\hline$\$ 1,000,001+$ & 4 Total Respondents \\
\hline Time-consuming to create and maintain models correctly & 3.00 \\
\hline Steep learning curve when training employees & 3.00 \\
\hline Difficult to find qualified, experienced employees & 4.25 \\
\hline High software costs & 4.50 \\
\hline Computer hardware needs to be substantial & 4.75 \\
\hline Lots of training is required to maintain effectiveness & 5.00 \\
\hline BIM software seems catered to commercial construction & 5.25 \\
\hline Different BIM platforms or versions are often incompatible & 8.00 \\
\hline Software platforms require updates for continued use & 8.50 \\
\hline Overabundance of information can overwhelm or confuse clients & 8.75 \\
\hline
\end{tabular}




\subsection{Questionnaire 3 Results}

The final questionnaire in this study was distributed in an effort to obtain consensus concerning all the data received in the first two questionnaires. We received 10 responses to questionnaire 3. The participants who responded consisted of five owners, three BIM managers, and two designers. The experts were asked to indicate their agreement with the various rankings and commonalities identified in questionnaire 2. The results of this questionnaire indicate that consensus was obtained in all but one area. The question concerning the most under-utilized use of BIM received only $50 \%$ consensus. None of the participants indicated why they disagreed with the ranking but one participant indicated that he mostly agreed, while stating that he "would love to develop this further."

Table 4.28: Questionnaire 3 Results

\begin{tabular}{|c|c|c|c|c|c|c|c|c|}
\hline \multirow[t]{2}{*}{ Question } & \multirow[t]{2}{*}{$\begin{array}{l}\text { Average } \\
\text { Agreement }\end{array}$} & \multicolumn{5}{|c|}{$\begin{array}{l}\text { \% of experts (10 Total) who } \\
\text { ranked as }\end{array}$} & \multicolumn{2}{|c|}{$\begin{array}{l}\text { \% of experts who } \\
\text { ranked as }\end{array}$} \\
\hline & & 5 & 4 & 3 & 2 & 1 & Agree & Disagree \\
\hline $\begin{array}{l}\text { Indicate your agreement with the implementation } \\
\text { process rankings. }\end{array}$ & 4.1 out of 5 & 10 & 90 & 0 & 0 & 0 & 100 & 0 \\
\hline $\begin{array}{l}\text { Indicate your agreement with the ranking of the } 3 \text { most } \\
\text { common uses of BIM in Custom Home Building. }\end{array}$ & 4.4 out of 5 & 50 & 40 & 10 & 0 & 0 & 90 & 0 \\
\hline $\begin{array}{l}\text { Indicate your agreement with the ranking of the benefits } \\
\text { of BIM in Custom Home Building. }\end{array}$ & 4.3 out of 5 & 50 & 30 & 20 & 0 & 0 & 80 & 0 \\
\hline $\begin{array}{l}\text { Indicate your agreement with the ranking of the } \\
\text { Challenges of BIM in Custom Home Building. }\end{array}$ & 4 out of 5 & 30 & 40 & 30 & 0 & 0 & 70 & 0 \\
\hline $\begin{array}{l}\text { Indicate your agreement with the statement "the } 3 \text { most } \\
\text { common uses of BIM in Custom Home building are } \\
\text { Design and Visualization, the creation of construction } \\
\text { Documents and Quantity Take-offs." }\end{array}$ & 3.7 out of 4 & N/A & 30 & 70 & 0 & 0 & 100 & 0 \\
\hline $\begin{array}{l}\text { Indicate your agreement with the statement, "the most } \\
\text { common under-utilized use of BIM in Custom Home } \\
\text { Building is Quantity Take-offs." }\end{array}$ & 2.8 out of 4 & N/A & 40 & 10 & 40 & 10 & 50 & 50 \\
\hline
\end{tabular}




\section{CONCLUSION}

The overall purpose of this study was to identify current best practices, benefits, and challenges associated with the use of BIM in custom home building companies in the United States. This provides a basis of understanding for companies desiring to implement BIM. This basis of understanding provided by experts within the industry would improve their chances for successful implementation.

\subsection{BIM in Custom Home Building}

Communication is crucial to the success of any project. This fact is perhaps even more poignant when applied to the construction industry. Many technological advances have taken place that increase the ease and effectiveness of communication in construction. One key technological advance that improves communication and overall project efficiency is Building Information Modeling or BIM. BIM has become a common tool among commercial general contractors worldwide and has provided multiple benefits to the industry. However, while BIM has been a key tool in commercial construction projects, it has yet to find its place in the residential construction sector.

The residential construction sector accounts for a significant portion of the construction that takes place in the United States and the segment of custom home building is defined as being similar to commercial construction in complexity. It is anticipated that BIM could provide 
similar benefits to the residential custom home construction sector as it does to the commercial sector. Therefore, the purpose of this study was to provide a basis of understanding for industry members seeking to implement BIM by identifying experts within the industry who currently utilize BIM to benefit their companies and receive answers to the following questions:

- What BIM software is being used?

- What is the best implementation process?

- What are the most common uses of BIM?

- What are the most common benefits of BIM?

- What are the most common challenges associated with BIM use?

These questions were answered through the Delphi method which utilizes a panel of experts and a series of questionnaires that are developed based on the responses to the preceding questionnaire. The goal of the panel was to achieve consensus on the topic in question. These experts were initially asked a series of demographic questions that would place them in various categories that would be easily identifiable for other home builders to compare with. The participants were asked to identify their location of business, the number of employees within their companies, the number of homes they complete each year, and the average sale price of their homes. As the locations of the participants were mainly limited to the Mountain West, South, and West Coast regions, there is potential application for other locations. It is also important to note that due to the selected research methodology, the panel size was small and the uses, benefits, and/or challenges identified by each demographic sector may not be generalized to the market. However, because the participants consisted of industry experts, the data provides a reference point because of their related experiences. 


\subsection{BIM Software}

There are multiple BIM software platforms available to the industry, but some are more popular than others. For a comprehensive list of BIM platforms that are available and a list of platforms that are more efficient for home builders, refer to the dissertation by Garcia and his associates entitled "Adoption of Building Information Modeling in Small Size Home-BuildingBusinesses." (Garcia, Mollaoglu (Korkmaz) and Syal 2016) The software identified by this panel as being used the most was Autodesk Revit ${ }^{\circledR}$. However, other platforms like Chief Architect ${ }^{\circledR}$ or $\operatorname{ArchiCAD}^{\circledR}$ were also identified by the panel.

\subsection{Implementation Process}

The research performed did not provide a distinct "best" implementation process for those wishing to implement BIM. All processes received an average ranking with only a one-point difference between the highest ranking and lowest ranking. However, it is important to note that, in questionnaire 1, while the number one implementation process that was utilized to implement BIM within the participant's companies was to hire experienced employees and the least utilized was to attend or watch training courses, the results from questionnaire 2 were the opposite from questionnaire 1 . This difference is between the implementation originally utilized by the participants as compared to the process they would use if they were to repeat the implementation process.

The number one ranked implementation process that they would utilize if they were to repeat the implementation process was to attend or watch training courses which could imply that company upper management is wanting to understand the process before expecting those who work for them to understand the process. It is understood that it is common practice in the 
commercial construction sector to have a BIM department with a BIM Coordinator who is responsible for the learning and dissemination of BIM knowledge. Thus, the upper management of a commercial company may have limited knowledge of BIM uses and benefits. This may be due to the size of the company and the sheer volume of work being performed. However, the data from this study could suggest that the upper management of smaller-volume home building companies wish to understand the process because BIM is potentially being used as an "allpurpose" tool by the company for marketing, visualization, etc. Also, because of the relatively small number of home builders using BIM, this gives them a competitive advantage. Thus, BIM is a company-wide tool and could essentially be seen as an essential driver for success.

\subsection{Most Common Uses of BIM}

The following uses of BIM were identified by this panel.

- Marketing

- Design and visualization

- Field management/corrections

- Creation of construction documents

- Design coordination and/or clash detection

- Scheduling

- Quantity take-offs or estimating

All uses identified in the study received a top three ranking by at least one participant signifying that they are being used to the benefit to the industry. However, the participants clearly indicate that their most common use of BIM was design and visualization across all demographic groups represented. Design and visualization received over a hundred percent higher ranking than the next closest ranked use identified by this panel. The creation of 
construction documents and quantity take-offs were also listed consistently throughout the study as common uses among all demographics. Design and visualization, the creation of construction documents, and quantity take-offs will be discussed in conjunction with benefits and challenges that could be associated with each use after the overall benefits and challenges have been discussed.

However, it is valuable to note that the most underutilized use of BIM identified by this panel was quantity take-offs, implying that there is a need for further development of that use within the industry.

The uses identified in this study correlate to the uses identified in the literature review. Design and visualization correlates with design authoring, field management/corrections correlates with $3 D$ control and planning, design coordination correlates with $3 D$ coordination, and quantity take-offs correlates with cost estimation. There is likely additional correlation between each list of uses but this simply shows some of the correlation between what has been identified in the literature and what the panel identified.

\subsection{Most Common Benefits of BIM}

Among this panel, client visualization, plan accuracy, improved client communication, and ease of plan revisions were ranked among the top benefits across all demographics. This correlates with the uses of BIM identified by this group. Design and visualization directly influences client visualization and improved client communication; and creation of construction documents directly influences the accuracy of plans and ease of plan revisions.

These benefits correlate to the benefits of BIM identified in the review of the literature. Table 2.1, which lists the benefits for each NAICS Construction Subsector, revealed a lack of 
research in the residential construction sector. This research provides support to the benefit of increased communication. This panel identified improved client communication, improved communication with/between trades, and other benefits specifically related to plans that could contribute to increased communication. While they do not correlate directly in name, the other benefits identified by this panel include increased project quality, increased trade coordination, increased productivity and reduced project costs. Improved communication and increased accuracy of plans may assist in improving the coordination between trades. Another example of this could be early identification of design errors and quicker, more accurate quantity take-off's or estimating reducing project costs. The only benefits identified in the literature review that had no potential relation to the benefits identified in this study was increased jobsite safety. The participants in this study did not indicate any benefits related to safety.

Table 5.1: Potential Relation of Benefits

\begin{tabular}{ll}
\hline Benefits identified in Literature Review & Benefits identified by this panel \\
\hline Increased Project Quality & Early identification of design errors \\
Reduced Project Costs & $\begin{array}{l}\text { Early identification of design errors; Quicker, } \\
\text { more accurate Quantity Take-off's or estimating }\end{array}$ \\
& $\begin{array}{l}\text { Improves Scheduling effectiveness; Quicker, } \\
\text { more accurate Quantity Take-off's or estimating; }\end{array}$ \\
Eecreased Project Schedule & $\begin{array}{l}\text { Ease of Plan Revisions } \\
\text { Improved Client communication; Improved } \\
\text { communication with/between trades; Early }\end{array}$ \\
identification of design errors; Ease of Plan \\
Revisions \\
Increased Productivity & \\
Increased Trade Coordination & $\begin{array}{l}\text { Improved communication with/between trades; } \\
\text { Ability to show plan from different angles } \\
\text { Client Visualization; Improved Client } \\
\text { communication; Improved communication } \\
\text { with/between trades; Ability to show plan from } \\
\text { different angles }\end{array}$ \\
\hline
\end{tabular}




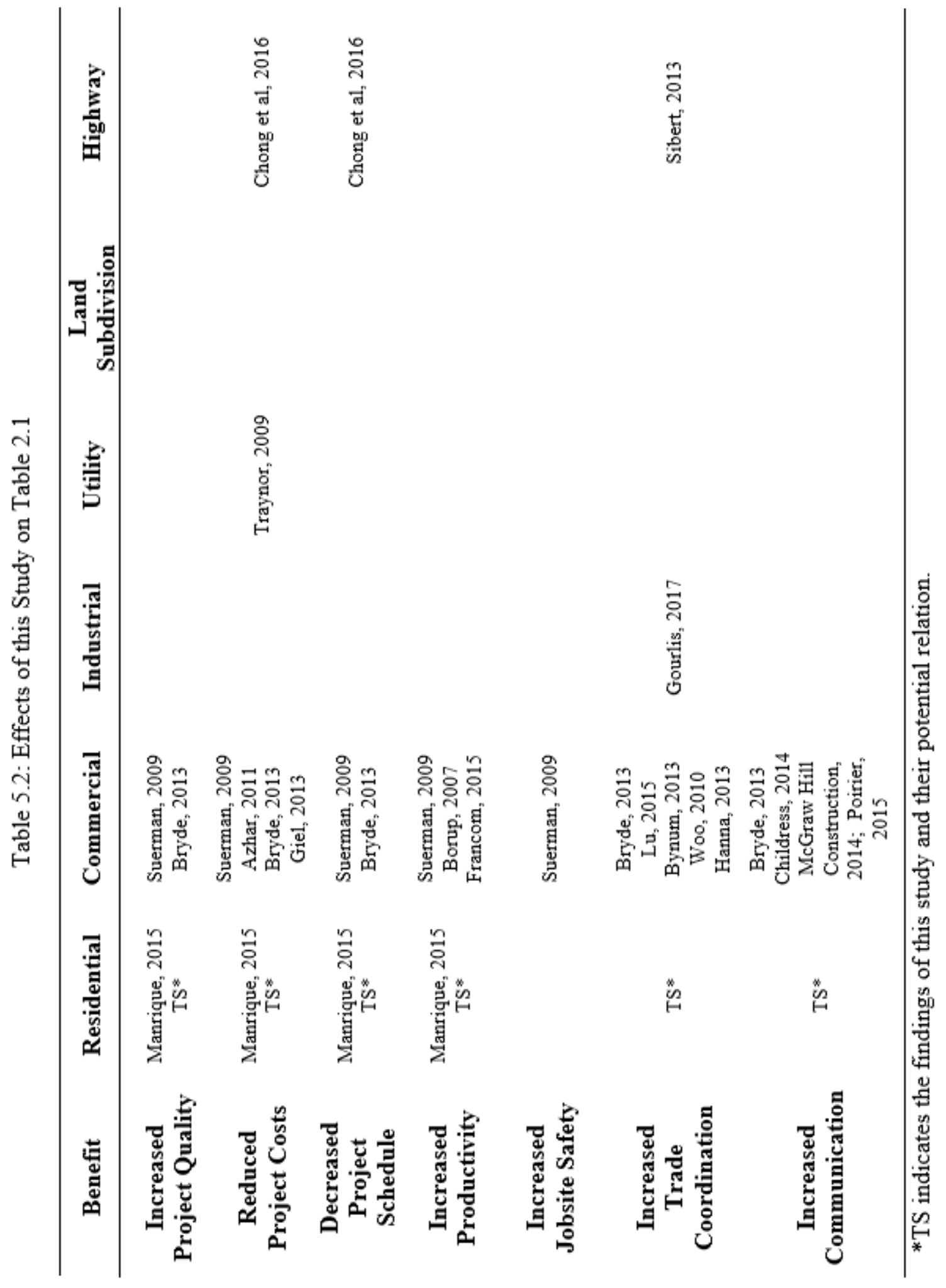




\subsection{Most Common BIM Challenges}

While the steep learning curve when training employees was the challenge that was ranked the highest by the panel, each demographic group selected their own individual greatest challenge. Eight of the challenges identified by this panel were ranked in the top three by at least one of the demographic groups. There are two challenges that were not ranked within the top three by any of the demographic groups, that BIM seems catered to commercial construction and that software platforms require updates for continued use. However, high software costs, the steep learning curve when training employees, and the time-consuming nature of creating and maintaining models correctly, were ranked among the top challenges faced by a majority of the panel.

\subsection{Further Discussion}

Every benefit identified by the panel is a potential result of at least one of the uses identified by the panel. However, many of the benefits and some of the challenges are potential results of just the top three uses identified. The top three uses and any potential resultant benefits and challenges were identified. The importance of any possible correlation identified here lies in how the affect the success factors identified by the 2005 study performed by Hutchings and Christofferson (Hutchings and Christofferson 2005). The uses and benefits that have been identified could directly affect these success factors and greatly improve a company's ability to perform their work.

\subsubsection{Design and Visualization}

Design and Visualization was by far the top use identified and only one of the participants did not list it as one of their top uses. This use can be directly tied to the benefit of client 
visualization, which was the top benefit identified by the panel and by a majority of the demographic groups represented within the panel. Because BIM features a 3D model of the product, a home in this case, clients are able to view homes in a 3D sphere, allowing them to get a more accurate picture of what the design looks like in a near life-like manner. This 3D sphere in relation to design and visualization also could be seen to result in the ability to show the plan from different angles. Clients are able to view other areas of the plan that would not otherwise be shown on traditional 2D plans, thus enhancing their ability to visualize what is being designed and make decisions. Because of the ability to show a plan from different angles and enhance the visualization aspect, design and visualization also has a correlation with improved client communication. However, this use could also be attributed with one of the challenges identified, the over-abundance of information that can confuse clients. Design and visualization applies to more than just the client, however. It also applies to the homebuilder and the trade contractors. Design and visualization could also result in improved communication with/between trades because the ability to show the plan from different angle as well as being able to visualize the plan in a 3D atmosphere enables the trades to see a fuller picture of the design.

The success factors that could be directly affected by this use and any subsequent benefits are a focus on product design and customer relations and communication. Design and visualization directly influences a focus on design and more likely is the driver of a focus on design. The customer relations and communications are improved because of the customer's ability to see graphically in 3D what may not necessarily be understood from a 2D plan view perspective. One could also argue that schedule/cycle time could also improve because of the ability to visualize the product and communicate more effectively any changes or decisions that needed to be made. Because these changes or decisions are being communicated more 
effectively, it could translate to being completed more quickly. However, as mentioned earlier, there may be a concern with too much information for clients. If there is too much information, there is potential for the client to get distracted by all the details and be unable to focus on specific decisions or needs of the project. An example of this was stated by a participant: "If we provide a BIM experience for a client in a draft phase of the design, certain clients can't see past an exposed $2 \times 4$ and we can't get good feedback on more important issues."

\subsubsection{Creation of Construction Documents}

The creation of construction documents could potentially be seen to produce a number of the benefits identified by the panel. Those benefits could include plan accuracy, early identification of design errors, and ease of plan revisions. These items are potentially correlated because of the nature of creating a BIM model. Because a model is created in 3D, any changes made in one area of a model are automatically updated in any other view where that area is shown. This increases the overall accuracy of construction documents, specifically where plan sheets have any cross-over in what is shown, makes revisions simpler because changes are automatically propagated throughout all views, and aids in the discovery of design errors because of the ability to view the plan from different angles. Similar to design and visualization, the creation of construction documents may also produce the benefits of improved client communication and improved communication with/between trades because they are able to see a fuller picture. One could also claim that this use could also benefit from the ability to show the plan from different angles because any 3D view can be translated to a 2D plan sheet. As one of the participants state in their description of the creation of construction documents use, "2D pages are a snap-shot of a detailed 3D model." However, creating a detailed 3D model takes time 
and, therefore, may result in the challenge that it is time consuming to create and maintain models correctly.

One can see how the use of the creation of construction documents could potentially improve the efficiency of the process as a whole. Fewer errors in the plans and a fuller picture of the project means less confusion during construction and a shorter construction process. But as mentioned earlier, the real importance lies in how these uses and benefits affect the success factors identified by Hutchings and Christofferson (Hutchings and Christofferson 2005). The success factors that may be affected by the use of the creation of construction documents are quality workmanship and products, customer communications and relations, and scheduling/cycle time. These success factors were affected because as plans become more accurate, the chances for confusion, both by the clients and the trades, decrease. As confusion decreases, quality increases, less errors occur in the field, and relations with the clients improve. This also decreases the cycle time because of the decrease in errors.

\subsubsection{Quantity Take-offs}

The use of BIM for quantity take-offs may have a more obvious correlation with the benefit of quicker, more accurate quantity take-offs or estimating. However, this quicker, more accurate take-off is reliant on an accurate model. Therefore, if the benefit of plan accuracy is not being seen then quantity take-offs may not be effective. This benefit was also listed as the most under-utilized, implying that more research is needed to identify how to improve the usefulness of BIM quantity take-offs within the industry. One participant stated that "Currently, it is just quicker, easier, and more accurate to do takeoffs by hand," and that "[he] would love to develop this further." 
This use and its benefit directly affects the success factor of competitive pricing/ product affordability because as quantity take-offs become more and more accurate, the need for contingencies and waste factors used while estimating decreases, which decreases the price to build. This improves the pricing and overall affordability of the product.

\subsection{Final Discussion and Recommendations}

The inter-relatability between the various uses, benefits and challenges can be substantial and should be considered. One use alone will not likely produce the desired return. Because the uses of BIM utilize a single model, the training and time required to utilize multiple uses may be considered minimal and the likelihood of a positive return on investment improves. Therefore, successful implementation may be based on the company's ability to learn and understand BIM uses, whether that is accomplished through hiring experienced employees, training current employees or self-led education of upper management. That understanding includes what the uses are, how they are used, and the benefits associated with each use.

It is recognized that some of the challenges identified by this group may pose a significant hurdle for BIM implementation. Therefore, it is recommended that those wishing to implement BIM utilize those uses identified by this study as providing the most benefit, namely, design and visualization, creation of construction documents, and quantity take-offs. Successful implementation has been achieved by the panel participants and may be possible for others wishing to implement BIM.

\subsection{Future Research Needs}

Following this research, a study that includes a larger sample that can be generalized to the market, as a whole, is necessary to determine market trends. Similarly, a study that seeks to 
identify why BIM is not being utilized within the residential sector to the same degree as commercial construction may be necessary to determine market concerns. A study that analyzes homeowners' perceptions and experiences as clients of home builders who utilize BIM in their processes would also provide crucial insight into the benefits of BIM from the perspective of the client. Research specific to the use of BIM for quantity take-offs was also mentioned specifically by the panel as an area were development is needed. In addition, any blank spaces in Table 2.1: Benefits identified in each NAICS Construction Subsector constitutes a need for research on the data corresponding to each blank space. 


\section{REFERENCES}

ADECA. "Community Development Block Grant Application Manual." Alabama Department of Economic and Community Affairs. 2015. http://adeca.alabama.gov/Divisions/ced/cdp/Pages/CDBG-Application-Manual.aspx.

Azhar, S. "Building Information Modeling (BIM): Trends, Benefits, Risks, and Challenges for the AEC Industry." Leadership and Management in Engineering 11, no. 3 (2011): 241252.

Beveridge, S. "Best Practices Using Building Information Modeling in Commercial Construction." ScholarsArchive. 2012. http://scholarsarchive.byu.edu/etd/3392/.

Bhoir, S. A., Schwab, A., Esmaeili, B., Goodrum, P. "A Decision-Making Algorithm for Selecting Building Information Modeling Functions." 5th International/11th Construction Specialty Conference. Vancouver, British Columbia, 2015. 202_1-202_10.

Borup, J. R. "Strategic Management and Risk Assessment Advice for Small Businesses in the Custom Home Building Industry." SSRN. August 20, 2007. https://ssrn.com/abstract=2846058 or http://dx.doi.org/10.2139/ssrn.2846058.

Bryde, D., Broquetas, M., Volm, J. M. "The project benefits of Building Information Modelling (BIM)." International Journal of Project Management, 2013: 971-980.

buildingSMARTalliance. "National BIM Standard-United States Fact Sheet 2015." National BIM Standard-United States. May 2015. https://www.nationalbimstandard.org/files/NBIMS-US_FactSheet_2015.pdf.

buildingSMARTalliance. The National BIM Standard-United States Version 3. Washington DC: Natoinal Institute of Building Sciences, 2015.

BLS; US Department of Labor; NAICS. Quarterly Census of Employment and Wages. Edited by US Department of Labor. 2017. https://www.bls.gov/cew/bls_naics/v1/bls_naics_app.htm\#tab=hierarchy\&naics $=2017 \& \mathrm{~h}$ ier=237_236 (accessed September 18, 2017).

Bynum, P., Issa, R. R. A, Olbina, S. "Building Information Modeling in Support of Sustainable Design and Construction." Journal of Construction Engineering and Management 139, no. 1 (January 2013).

Cadazz. CAD software - history of CAD CAM. 2004. http://www.cadazz.com/cad-softwarehistory.htm (accessed January 30, 2016). 
Cambeiro, F. P., Barbeito, F. P., Castaño, I. G., Bolíbar, M. F., Rodríguez, J. R. "Integration of Agents in the Construction of a Single-Family House Through use of BIM Technology." Procedia Engineering 69 (2014): 584-593.

Childress, V. W. "Building Construction and Building Information Modeling." Technology and Engineering Teacher, December 2014: 24-29.

Chong, H. Y., Lopez, R., Wang, J., Wang, X., Zhao, Z. "Comparative Analysis on the Adoption and Use of BIM in Road Infrastructure Projects." Journal of Management in Engineering 32, no. 6 (2016).

CIC. BIM Execution Planning. Penn State University. 2011. http://bim.psu.edu/default.aspx.

Construction Industry Institute. Making Zero Rework a Reality. Austin, TX: Construction Industry Institue, 2005.

Department of Finance and Administration. "BIM Standards." Office of the State Architect. July 29, 2015. https://www.tn.gov/assets/entities/finance/osa/attachments/BIM_Standards_20150729.pd f.

Eastman, C., Teicholz, P., Sacks, R., Liston, K. BIM Handbook: A Guide to Building Information Modeling for Owners, Managers, Designers, Engineers, and Contractors. John Wiley \& Sons Inc., 2008.

Eveland, C. K., Caven III, J. W., Menzel, R. B. United States Patent US9529868 B1. 2016.

Ford, C. "Popularity of Building Information Modeling Increases Among NAHB Members." Eye on Housing. December 13, 2016. http://eyeonhousing.org/2016/12/popularity-ofbuilding-information-modeling-increases-among-nahb-members/.

Francom, T. C., El Asmar, M. "Project Quality and Change Performance Differences Associated with the Use of Building Information Modeling in Design and Construction Projects: Univariate and Multivariate Analyses." Journal of Construction Engineering and Management 141, no. 9 (April 2015).

Garcia, A. J., Mollaoglu (Korkmaz), S., Syal M. "Adoption of Building Information Modeling in Small Size Home-Building-Businesses." PhD Dissertation Submitted to The Michigan State University Construction Management Program, 2016.

Giel, B. K., Issa R. R. A. "Return on Investment Analysis of Using Building Information Modeling in Construction." Journal of Computing in Civil Engineering 27, no. 5 (September 2013).

Gourlis, G., Kovacic, I. "Building Information Modelling for Analysis of Energy Efficient Industrial Buildings - A Case Study." Renewble and Sustainable Energy Reviews (Elsevier) 68 (2017): 953-963. 
Hanna, A. S. Construction Labor Productivity Management and Methods Improvement. Hanna Consulting, 2010.

Hanna, A., Boodai, F., El Asmar, M. "State of Practice of Building Information Modeling in Mechanical and Electrical Construction Industries." Journal of Construction Engineering and Management, June 2013.

Hutchings, M., Christofferson, J. "Factors Leading to Construction Company Success: Perceptions of Small-Volume Residential Contractors." Associated Schools of Construction Journal, 2005.

Jackson, B. J. "Construction Management Jumpstart." 11-15. Wiley Publishing Inc., 2010.

Levy, S. M. Project Management in Construction. McGraw Hill Professional, 2006.

Lu, W., Fung, A., Peng, Y., Liang, C., Rowlinson, S. "Demystifying Construction Project TimeEffort Distribution Curves: BIM and Non-BIM Comparison." Journal of Management in Engineering 31, no. 6 (2015).

Manrique, J. D., Al-Hussein, M., Bouferguene, A., Nasseri, R. "Automated generation of shop drawings in residential construction." Automation in Construction 55 (2015): 15-24.

Mark, E., Gross, M., Goldschmidt, M. "A Perspective on Computer Aided Design after Four." 26th eCAADe conference proceedings. Antwerpen, Netherlands, 2008. 169-176.

McGraw Hill Construction. SmartMarket Report: The Business Value of BIM for Owners. McGraw Hill Construction, 2014.

McGraw Hill Construction. SmartMarket Report: The business Value of BIM in North America. McGraw Hill Construction, 2012.

McGraw-Hill. The Business Value of BIM: Getting Building Information Modeling to the Bottonm Line. Smart Market Report, 2009.

Mills, A., Love, P. E. D., Williams, P. "Defect Costs in Residential Construction." Journal of Construction Engineering and Management (ASCE) 135, no. 1 (January 2009): 12-16.

NAHB. 2014 Building Information Modeling Survey. The National Association of Home Builders, 2014.

NAHB. 2016 Building Information Modeling (BIM) Survey. The National Association of Home Builders, 2016.

NAHB. "Bulding Information Modeling (BIM)." The National Association of Home Builders. October 10, 2012. http://www.nahb.org/ /media/Sites/NAHB/SupportingFiles/2/BIM/BIM_final_20130930 084545.ashx. 
NAHB. Custom Homes. 2017. https://www.nahb.org/en/consumers/home-buying/types-of-homeconstruction/types-of-home-construction-custom-homes.aspx (accessed December 2, 2017).

Nellis, S. "Building Information Modeling: Is it Right for North Texas Home-Builders?" Master Thesis submitted to the Construction Management Program at East Carolina, 2012.

New Mexico Administrative Code. 1.5.18.9.

Ohio DAS General Services Division. "State of Ohio Building Information Modeling Protocol." State Architect's Office. September 29, 2010. http://das.ohio.gov/Portals/0/DASDivisions/GeneralServices/SAO/pdf/SAOBIMProtocol.pdf.

Poirier, E. A., Staub-French, S., Forgues, D. "Assessing the performance of the building information modeling (BIM) implementation process within a small specialty contracting enterprise." Canadian Journal of Civil Engineering 42 (2015): 766-778.

Quint, R. "Profile of the Typical Single-Family Builder in 2009." National Association of Home Builders. July 1, 2010. https:/www.nahb.org/en/research/housing-economics/specialstudies/archives/profile-of-typical-single-family-builder-2009.aspx.

Quint, R. US Government: Number of Builders Declined 50\% Between 2007 and 2012. September 9, 2015. http://eyeonhousing.org/2015/09/us-government-number-of-buildersdeclined-50-between-2007-and-2012/.

Robinson, C., O'Leary, B., Rincon, A. "Business start-ups, closures and economic churn: a review of the literature." Enterprise Directorate, BERR, UK, 2006.

Rosenbloom, S. How Does BIM Change Your Project Processes and Where Does Revit Fit In? April 6, 2011. http:/www.bimuzer.com/2011/04/06/how-does-bim-change-your-projectprocesses-and-where-does-revit-fit-in-2/ (accessed January 30, 2017).

Sibert, B. "Using Building Information Modeling on a Highway Project." Proceedings of the Institution of Civil Engineers-Civil Engineering. Institution of Civil Engineers, 2013. 9.

Smith, J. P. "Best Practices for Dealing with Price Volatility in Utah's Residential Construction Market." International Journal of Construction Education and Research 7 (2011): 210225.

Sourani, A., Sohail, M. "The Delphi Method: Review and Use in Construction Management Research." International Journal of Construction Education and Research 11 (2015): 5476.

Succar, B. "Building information modelling framework: A research and delivery foundation for industry stakeholders." Automation in Construction 18 (2009): 357-375. 
Suermann, P. C., Issa, R. R. A. "Evaluating Industry Perceptions of Building Information Modeling (BIM) Impact on Construction." Journal of Information Technology in Construction 14 (2009).

The Infrastructure and Projects Authority. "Government Construction Strategy." 2016.

Thomson, D. B., Miner, R. G. "Building Information Modeling - BIM: Contractual Risks are Changing with Technology ." Fabyanske, Westra, Hart \& Thomson Law Breifing Papers. August 6, 2016. http://fwhtlaw.com/briefing-papers/building-information-modeling-bim/.

Traynor, M., Sawyer, T., Rubin, D. "Bending BIM to Design Utilities Breaks New Ground." Engineering News-Record, August 10, 2009: 31.

U. S. Census Bureau. "2014 SUSB Annual Data Tables by Establishment Industry." United States Census Bureau. 2014. https://www.census.gov/data/tables/2014/econ/susb/2014susb-annual.html.

U. S. Census Bureau. Construction Spending. December 2016. https://www.census.gov/construction/c30/c30index.html.

Wisconsin DOA. "Building Information Modeling." Wisconsin Department of Administration. July $1,2009$. ftp://doaftp1380.wi.gov/master_spec/BIM\%20Guidelines\%20\&\%20Standards/BIM_Gui delines_and_Standards\%206-09.pdf.

Woo, J., Wilsmann, J., Kang, D. "Use of As-Built Building Information Modeling." Construction Research Congress. 2010. 538-548.

Zuppa, D., Issa, R. R. A., Suermann, P. C. "BIM's Impact on the Success Measures of Construction Projects." Computing in Civil Engineering, 2009: 503-512. 
APPENDICES 
APPENDIX A. LIST OF EXPERT PANEL MEMBERS

\begin{tabular}{|l|l|l|}
\hline \multicolumn{1}{|c|}{ Company Name } & Expert & $\begin{array}{l}\text { State of Primary } \\
\text { Location }\end{array}$ \\
\hline Van Sickle Design & Bill Van Sickle & Utah \\
\hline Cardinal Crest Homes & Joe Christensen & Kansas \\
\hline Ezra Lee Design Build & Kelly & Utah \\
\hline Heartwood Design Build & Tomas Salinas & California \\
\hline Jeff Watson Homes & Ken Doocy & Texas \\
\hline Markay Johnson Construction & Chad Broadhead & Utah \\
\hline Montana Heritage Home Builders & Allen Ream & Montana \\
\hline Natural Builders LLC & Thomas Soule & New Mexico \\
\hline Pioneer West Homes & Kristi Grabill & Colorado \\
\hline South Fork Design Group & Ray & Idaho \\
\hline Trails End Home Builders & Shawn & Colorado \\
\hline Tresidio Homes & Dallin Fogle & Idaho \\
\hline Trilogy Partners & Lars Zimmerman & Colorado \\
\hline Green Design Build & Larry & Texas \\
\hline Jenkins Design Build & Mark Lakins & Texas \\
\hline RA Nelson & Ryan Lavire & Colorado \\
\hline Starwood Custom Homes & Travis Allen & Arizona \\
\hline Sun Forest Construction & Laurie Moar & Oregon \\
\hline
\end{tabular}


APPENDIX B. QUESTIONNAIRE 1

\section{Building Information Modeling Questionnaire 1}

Where are you located? (Select all that apply)

West Coast
Mountain West
Eulf Coast
South
Other (please list)


How many people does your company employ?

$1-10$

$11-25$

$26-50$

$50+$

How many homes do you complete each year?
$0-10$
$11-30$
$31-60$
$61+$

What is the average sale price of your homes?

Up to $\$ 250,000$

$\$ 250,001-\$ 500,000$

$\$ 500,001-\$ 750,000$

$\$ 750,001-\$ 1,000,000$

$\$ 1,000,001+$ 
What does your company specialize in? (select all that apply)

New home construction

Remodels

Home additions

What software platforms do you use?

ArchiCAD

Bentley

Vectorworks

DataCAD

Revit

Sketchup

Other (please specify)

What was your process for implementing BIM? (i.e. trained a current employee, hired an experienced employee, etc.) 
How is BIM used in your company? (multiple answers encouraged if applicable)

What benefits of BIM use have you identified in your company?

\section{Benefit 1}

\section{Benefit 2}

\section{Benefit 3}


Benefit 4

Benefit 5

Benefit 6

Benefit 7 
Benefit 8

\section{Benefit 9}

\section{Benefit 10}

What challenges related to BIM use have you identified in your company?

\section{Challenge 1}


Challenge 2

Challenge 3

Challenge 4

\section{Challenge 5}


Challenge 6

Challenge 7

Challenge 8

Challenge 9 
Challenge 10

If you have any other comments, you may write them here. 


\section{APPENDIX C. $\quad$ QUESTIONNAIRE 2}

\section{Building Information Modeling Questionnaire 2}

Thank you for your continued involvement in this study on the current state of BIM implementation within the custom home building industry. The questions in this questionnaire were developed from the responses received previously in questionnaire 1. Your answers will help clarify and expand on the information gathered during questionnaire 1.

Based on your experience, what process would you use to implement BIM if you were to have to do it again? Please rank the different methods below from $1=$ most likely to use to $4=$ least likely to use.

Self-led education

Hire experienced employees

Train current employees

Attend or watch training courses 
Please select the three (3) most common uses of BIM within your company.

Marketing

Design and visualization

Field management/corrections

Creation of construction documents

Design coordination and/or clash detection

Scheduling

Quantity take-offs or estimating

Please rank your top three uses: $1=$ most commonly utilized to $3=$ least commonly utilized .

Marketing

Design and visualization

Field management/corrections

Creation of construction documents

Design coordination and/or clash detection

Scheduling

Quantity take-offs or estimating 
Are there any of the uses listed below that your company either does not or rarely utilizes? Please select all that apply.

Marketing

Design and visualization

Field management/corrections

Creation of construction documents

Design coordination and/or clash detection

Scheduling

Quantity take-offs or estimating

Are there any of the uses listed below that are under-utilized within your company? Please select all that apply.

Marketing

Design and visualization

Field management/corrections

Creation of construction documents

Design coordination and/or clash detection

Scheduling

Quantity take-offs or estimating 
Rank the benefits listed below from $1=$ most beneficial to $10=$ least beneficial to your organization.

Plan accuracy

Client visualization

Quicker, more accurate quantity take-off's or estimating

Improved client communication

Improved communication with/between trades

Improves scheduling effectiveness

Early identification of design errors

Improved marketing materials (i.e. renderings)

Ease of plan revisions

Ability to show plan from different angles

Rank the challenges listed below from $1=$ most challenging to $10=$ least challenging for your organization.

High software costs

Steep learning curve when training employees

Time consuming to create and maintain models correctly

Overabundance of information can overwhelm or confuse clients

Lots of training is required to maintain effectiveness

Computer hardware needs to be substantial

Different BIM platforms or versions are often incompatible

Bim software seems catered to commercial construction

Software platforms require updates for continued use

Difficult to find qualified, experienced employees

If you have any other comments, you may write them here. 


\section{APPENDIX D. QUESTIONNAIRE 3}

\section{Building Information Modeling Questionnaire 3}

Thank you for your continued involvement in this study on the current state of BIM implementation within the custom home building industry. This will be the final questionnaire in the study. The goal of this final questionnaire is to assess the level of consensus within the group. The questions in this questionnaire were developed from the responses received previously in questionnaire 2. Your answers will help clarify and expand on the information gathered during questionnaire 2 .

According to the data gathered related to the question in questionnaire 2 concerning what method would be used if you were to go through the implementation process again, the methods of implementation were ranked as follows: $(1=$ most preferred method and $4=$ least preferred method):

1. Attend or watch training courses

2. Hire an experienced employee

3. Train current employees

4. Self-led education

Please indicate the level of your agreement with this ranking.

Completely Disagree

Mostly Disagree

Neither Agree nor Disagree

Mostly Agree

Completely Agree 
If you have any comments that describe why you agree or disagree, you may write them here. (Optional)

According to this expert panel, the three most common uses of BIM in custom home building are:

1. Design visualization

2. Creation of construction documents

3. Quantity take-offs.

Please indicate the accuracy of this statement based on your experience.

Completely Inaccurate

Mostly Inaccurate

Mostly Accurate

Completely Accurate

The three most common uses were ranked as follows:

1. Design visualization

2. Creation of construction documents

3. Quantity take-offs

Please indicate your agreement with this ranking.

Completely Disagree

Mostly Disagree

Neither Agree nor Disagree

Mostly Agree

Completely Agree 
If you have any comments that describe why you agree or disagree, you may write them here. (Optional)

According to this panel, the most common under-utilized use of BIM in custom home building is quantity take-offs.

Please indicate the accuracy of this statement, based on your experience.

Completely Inaccurate

Mostly Inaccurate

Mostly Accurate

Completely Accurate

If you have any comments that describe why you agree or disagree, you may write them here. (Optional) 
According to data received in questionnaire 2, the previously identified benefits of BIM were ranked as follows:

1. Client visualization

2. Plan accuracy

3. Improved client communication

4. Early identification of design errors

5. Ease of plan revisions

6. Ability to show plans from different angles

7. Quicker, more accurate quantity take-offs or estimating

8. Improved communication with/between trades

9. Improved schedule effectiveness

10. Improved marketing materials (i.e. renderings)

Please indicate your agreement with this ranking.

Completely Disagree

Mostly Disagree

Neither Agree nor Disagree

Mostly Agree

Completely Agree

If you have any final thoughts about the benefits of BIM you may write them here. (Optional) 
According to data received in questionnaire 2, the previously identified issues or challenges of BIM were ranked as follows:

1. Steep learning curve when training employees

2. Time-consuming to create and maintain models correctly

3. High software costs

4. Lots of training required to maintain effectiveness

5. Computer hardware requirements

6. Difficult to find qualified, experienced employees

7. BIM software seems catered to commercial construction

8. Different BIM platforms or versions are often incompatible

9. Overabundance of information can overwhelm or confuse clients

10. Software platforms require updates for continued use

Please indicate your agreement with this ranking.

\section{Completely Disagree}

Mostly Disagree

Neither Agree nor Disagree

Mostly Agree

Completely Agree

If you have any comments that describe why you agree or disagree, you may write them here. (Optional) 
Would you like to receive a copy of the final results of this study?

Yes

No

Please list the email you would like these results sent to.

Email: 